\title{
Surface Mixing by Geostrophic Flows in the Bay of Bengal
}

\author{
Nihar Paul and Jai Sukhatme \\ Centre for Atmospheric and Oceanic Sciences, \\ Indian Institute of Science, \\ Bangalore 560012, India
}

\begin{abstract}
Mixing of passive tracers in the Bay of Bengal, driven by altimetry derived daily geostrophic surface currents, is studied on subseasonal timescales. To begin with, Hovmöller plots, wavenumber-frequency diagrams and power spectra confirm the multiscale nature of the flow. Advection of latitudinal and longitudinal bands immediately brings out the chaotic nature of mixing in the Bay via repeated straining and filamentation of the tracer field. A principal finding is that mixing is local, i.e., of the scale of the eddies, and does not span the entire basin. Indeed, Finite Time Lyapunov Exponent (FTLE), Relative Dispersion (RD) and Finite Size Lyapunov Exponents (FSLE) maps in all seasons are patchy with minima scattered through the interior of the Bay. Further, FTLE, FSLE and RD maps show that the Bay experiences a seasonal cycle wherein rapid stirring progressively moves from the northern to southern Bay during pre and post monsoonal periods, respectively. The non-uniform stirring of the Bay is reflected in long tailed histograms of FTLEs, that become more stretched for longer time intervals. Quantitatively, advection for a week shows the mean FTLE lies near 0.15-0.16 day ${ }^{-1}$, while extremes reach almost $0.5 d a y^{-1}$. Averaged over the Bay, RD initially grows exponentially, this is followed by a powerlaw at scales between approximately 100 and $250 \mathrm{~km}$, which finally transitions to an eddy-diffusive regime. These findings are confirmed by FSLEs; in addition, quantitatively, below $250 \mathrm{~km}$, a scale dependent diffusion coefficient is extracted that behaves as a power-law with cluster size, while above $250 \mathrm{~km}$, eddy-diffusivities range from $6 \times 10^{3}-10^{4} \mathrm{~m}^{2} / \mathrm{s}$. Finally, in concert with satellite salinity data, these Lagrangian tools are used to analyse a single post-monsoonal fresh water mixing event. Here, while stirring the salinity field at large scales, FTLEs and FSLEs allow the identification of transport barriers, and elucidate how individual eddies help preserve the identity of fresh water.
\end{abstract}

\section{INTRODUCTION}

Advective transport and mixing is an important aspect of geophysical flows [82]. For example, in the oceans, surface stirring plays a key role in determining the fate of chemical and biological fields. Stirring affects dispersal from localized sources [for example, 46, 50, 53], as well the spatial and statistical distribution of large scale inhomogeneities [for example, 2]. The coupling of advective mixing with sinks and sources (other than diffusion) has also proved useful in a geophysical context. For example, advection-linear damping [27], to understand the patchiness of biogeochemical tracers in the ocean with differing lifetimes [48], advection-reactiondiffusion [51], to elucidate the formation and sustenance of plankton blooms [37] and advection-condensation [58], to probe the large-scale distribution of water vapor in the atmosphere [74]. In fact, advection-reaction models have also found use in extraplanetary scenarios, such as understanding seasonal variations in atmospheric composition [45].

In a two-dimensional (2D) setting, it is well known that even relatively simple time dependent flows can lead to complicated tracer patterns [7]. An up-to-date review of chaotic mixing, and more broadly mixing implied by multiscale flows, can be found in [8], and an overview of applications and methods in an oceanographic context can be found in [62]. Along with conventional measures such as relative dispersion, regular and anomalous diffusion, Lagrangian tools from dynamical systems such as Finite Time Lyapunov Exponents (FTLEs) and Finite Size Lyapunov Exponents (FSLEs) have proved useful in quantifying stirring via simple mixing protocols as well as multiscale turbulent flows. Examples in an oceanic context include, uncovering the mechanisms underlying inter- gyre mixing [59, 83], transport across jets [65], localized stirring in ocean basins such as the Adriatic [44], Tasman [79] and Mediterranean Sea [33], to elucidate the non-uniform nature of surface mixing [78], identification of mesoscale eddies [16] and relative dispersion [28], in the global oceans. In addition to quantifying rates of mixing, these tools also allow for the identification of kinematic transport barriers, i.e., transient structures that inhibit global mixing in geophysical flows [17].

In the present work, we bring some of these tools to bear on intraseasonal mixing by geostrophic currents in the Bay of Bengal $(\mathrm{BoB})$ which is a triangular basin spanning $5^{\circ}-22^{\circ} \mathrm{N}$ and $80^{\circ}-100^{\circ} \mathrm{E}$, centered around $15^{\circ} \mathrm{N}$. Apart from an influence on biological activity [for example, evolution of plankton blooms, 75] and better understanding the dispersal of contaminants [for example, the February 2017 oil spill near Chennai[84]], the Bay is an exciting playground with a myriad of seasonal and intraseasonal features. Specifically, the surface flow in the Bay is marked by seasonal features that include an intensified western boundary current that flows northward (equatorward) before (after) the summer monsoon and relatively steady eddies off the eastern coast of India during the monsoon itself $[66,77]$. In addition, altimetry data suggests that the Bay has significant intraseasonal variability in surface geostrophic currents [26]. In the midst of this activity, another interesting aspect of the Bay is that it is an open basin. In particular, the Bay is connected to the Equatorial Indian Ocean on the southern side and also receives a large amount of fresh water from various river mouths in the northern portion. Much of this river inflow is in the post monsoonal period and comes from Ganga-Brahmaputra and Irrawaddy river basins [22, 55]. In fact, this inflow and its transport is clearly seen in measurements of salinity as well as in numer- 
ical simulations $[4,67,68]$, and its dispersal plays an important role in the surface salinity budget of the Bay [38]. Taken together, this makes for an interesting dynamical setting in which to assess and quantify the mixing and dispersal of passive tracers.

The outline of this manuscript is as follows: in Section 2, we describe the data used in this study. Section 3 provides an overview of the geostrophic flow from physical and spectral points of view. This gives us a feel for the flow that is responsible for the intraseasonal advection of the passive tracers. Beginning with the advection of latitudinal and longitudinal stripes, in Section 4, we describe and compute FTLEs, Relative Dispersion (RD) and FSLEs. Seasonal mean maps and histograms of these measures are presented so as to quantify rates and scales, as well as the non-uniformity of chaotic mixing in the Bay. The FSLEs are also used to estimate finite scale diffusion coefficients as well as region dependent large scale eddy diffusivities in the Bay. Finally, we use these tools (FTLE \& FSLE) to examine a particular mixing event, specifically, the shielding of postmonsoonal fresh water in OctoberNovember 2015 by a persistent eddy in the northern Bay. A discussion and summary of results concludes the paper.

\section{DATA}

The Ssalto Duacs/gridded multimission altimeter products, which are a part of AVISO project (http: //www.aviso.altimetry.fr/en/home.html), have been used in this study. Specifically, we use MADTH-UV (Maps of Absolute Dynamic Topography \& Absolute Geostrophic Velocities) datasets with a spatial resolution of $0.25^{\circ} \times 0.25^{\circ}$, covering $5^{\circ} \mathrm{N}$ to $24^{\circ} \mathrm{N}$ and $80^{\circ} \mathrm{E}$ to $100^{\circ} \mathrm{E}$ on a Cartesian grid. To verify the robustness of our results we have used multiple years of data, specifically, 20102013. For salinity, we have used the Level-3 SMAP SSS version-3 data set produced by the Jet Propulsion Laboratory (https://podaac.jpl.nasa.gov/dataset/ SMAP_RSS_L3_SSS_SMI_8DAY-RUNNINGMEAN_V2? ids=Collections\&values=SMAP - SSS) at $0.25^{\circ}$ horizontal resolution and 8 day running average time window from 31 March 2015 to 31 December 2015.

Based on its general circulation [61], the Bay has been divided into four different regions in this study - Northern Bay (NB $\left.\rightarrow 15.125^{\circ} \mathrm{N}-20.125^{\circ} \mathrm{N}, 86.625^{\circ} \mathrm{E}-92.625^{\circ} \mathrm{E}\right)$, Central Bay $\left(\mathrm{CB} \rightarrow 10.125^{\circ} \mathrm{N}-14.875^{\circ} \mathrm{N}, 81.125^{\circ} \mathrm{E}-92.125^{\circ} \mathrm{E}\right)$, Southern Bay $\left(\mathrm{SB} \rightarrow 5.125^{\circ} \mathrm{N}-9.875^{\circ} \mathrm{N}, 82.125^{\circ} \mathrm{E}-93.125^{\circ} \mathrm{E}\right)$ and Andaman Sea (AS $\rightarrow 6.125^{\circ} \mathrm{N}-15.125^{\circ} \mathrm{N}, 93.375^{\circ} \mathrm{E}-$ $97.375^{\circ} \mathrm{E}$ ). The geographic locations of these boxes are shown in Figure 1. This division, and expected heterogeneity in mixing, is based on the general circulation of the Bay [61], the natural partitioning provided by the Andaman Islands and the inflow of fresh water that distinguishes the northern and southern portions of the Bay.

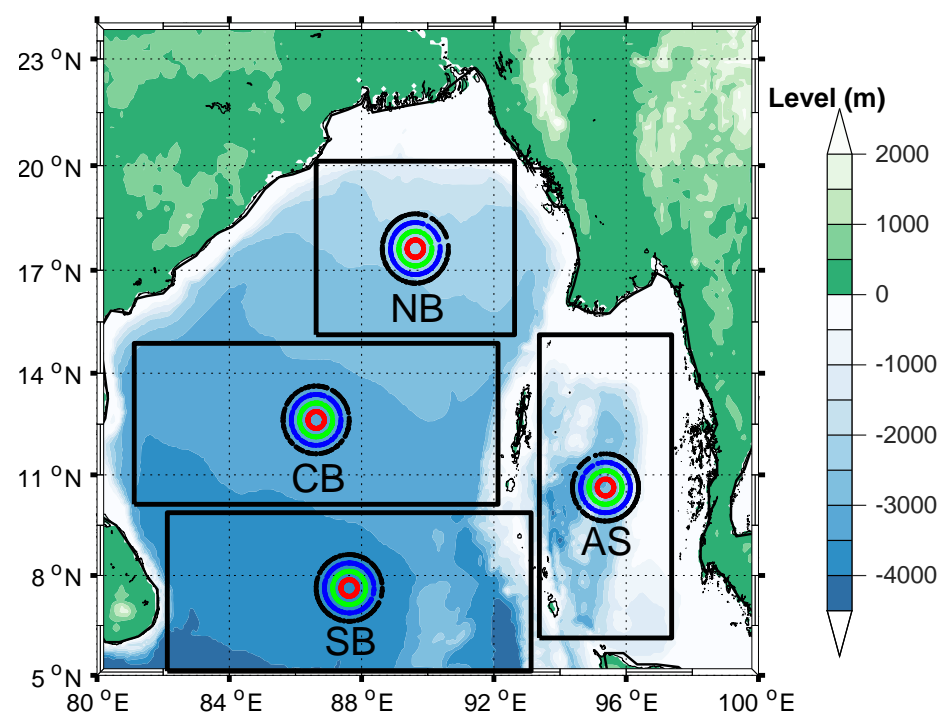

FIG. 1: The Bay of Bengal and subregions [Northern Bay (NB), Central Bay (CB), Southern Bay (SB) and Andaman Sea (AS)].

\section{CIRCULATION IN BAY OF BENGAL}

Given its importance to the regional climate, the seasonal circulation of the BoB has been studied quite extensively [see for example, 61, 66, 77], and we refer the readers to the aforementioned papers for details. Here, we provide an overview of the subseasonal surface geostrophic circulation to get a feel for the flow that is responsible for advection in the subsequent passive tracer mixing experiments.

\section{A. Physical space characterization}

On intraseasonal timescales, in the context of geostrophic surface flows, the co-existence of Rossby waves and (nonlinear) eddies is well established throughout the world's oceans [see for example, 23]. In the BoB too, a rich interplay of Rossby waves and eddies has been noted in numerous studies [for example, 10, 25, 41, 52, 69]. It has been suggested that the west coast of the Bay is a critical region for eddy-mean flow interaction with significant baroclinic instability and the production of eddies $[25,41,52]$. Further, eddies in the BoB have different propagation characteristics in different regions. For example, eddies in the northern and southern Bay (i.e., north of $15^{\circ} \mathrm{N}$ and south of $10^{\circ} \mathrm{N}$ ) propagate in southwestward and northwestward directions, respectively. While those in the central Bay tend to move in along the same latitude in a westward direction [25].

We begin with Hovmöller plots with respect to longitude of the zonal geostrophic velocity in different seasons of all the four years (meridional velocities show essentially similar features). The longitude spans $80^{\circ} \mathrm{E}$ to $100^{\circ} \mathrm{E}$, with the latitude being fixed at the Central Bay (this is the widest portion of the Bay, hence allows for a clear observation of the east- 
west movement of disturbances), specifically, $12.125^{\circ} \mathrm{N}$. As seen in Figure 2, throughout the year we observe southeast to northwest tilted coherent structures. The tilts are fairly steady across the years and yield a westward phase speed of approximately $8-12 \mathrm{~cm} / \mathrm{s}$, consistent with prior estimates from the central BoB [23, 25, 40]. Interestingly, these cohesive southeast to northwest tilting structures, or wave packets, also appear to exhibit episodic eastward migration with systematic positive (red) and negative (blue) anomalies. Specific examples are : March to July between $85^{\circ} \mathrm{E}$ to $95^{\circ} \mathrm{E}$ in 2010 , February to May around $85^{\circ} \mathrm{E}$ and October to December between $85^{\circ} \mathrm{E}$ and $90^{\circ} \mathrm{E}$ in 2011 , October to December between $85^{\circ} \mathrm{E}$ to $90^{\circ} \mathrm{E}$ in 2012 and February to May around $85^{\circ} \mathrm{E}$ in 2013 . These suggest a small eastward group velocity associated with these wave packets. We have also constructed Hovmöller plots of the zonal velocity with respect to latitude (not shown), these showed a fairly mixed behavior with sporadic instances of northward and southward tilts. By and large, the movement of disturbances in the East-West direction in the Bay is more pronounced and systematic as compared to North-South migration.

\section{B. Spectral space characterization}

To get a feel for the scale and time period of these disturbances we move to spectral space and compute wavenumberfrequency diagrams of the sea level anomaly (SLA) constructed from MADT-H. The climatological mean has been removed from the data to construct the SLA and then it is subjected to a 30-120 day band pass Lanczos filtering, with number of coefficient equals to 100 . The results presented are averaged over a latitude band from $14.125^{\circ} \mathrm{N}$ to $15.125^{\circ} \mathrm{N}$ (through the central and widest longitudinal extent of the Bay, and for consistency with the Hovmöller plots). As seen in Figure 3(a), we note strong spectral peaks spread over $\left|k_{x}\right| \approx$ $1-5$ for $k_{x}<0$, with time periods ranging from about 35 to 100 days. The three solid curves shown in Figure 3(a) correspond to the dispersion relations of baroclinic Rossby modes given by,

$$
\sigma=-\frac{\beta k_{x}}{{k_{x}}^{2}+k_{y}^{2}+\frac{1}{L_{R}^{2}}}, \text { for } k_{y}=1,2,3
$$

Here, $k_{x}$ and $k_{y}$ are the zonal and meridional wavenumber and $L_{R}$ is the Rossby radius of deformation. The wavenumbers have been normalized by the length of the BoB which is equal to $1800 \mathrm{~km}\left(72 \times 1 / 4^{\circ}\right)$ at $15^{\circ} \mathrm{N}$. The typical value of $L_{R}$, lies between $50-100 \mathrm{~km}$ over the latitudes spanned by the Bay [24]. In fact, following [70], we estimated an "eddy length scale" from zero crossing of autocorrelation function of the SSH. This estimate (not shown) is somewhat larger than $L_{R}$, and varies from $125-165 \mathrm{~km}$ over $18^{\circ} \mathrm{N}$ and $5^{\circ} \mathrm{N}$. The peaks in the left half of Figure 3(a) correspond to westward phase speeds, and they appear to be guided by Equation 1. This suggests that these disturbances with westward phase speed are related to baroclinic Rossby waves. Further, the position of the maxima in these diagrams show that there is significant power at scales just smaller than the local deformation scale (maxima of the dispersion curves), thus supporting episodic eastward group velocities noted in the longitudinal Hovmöller plots in Figure 2.

We also computed a dispersion diagram of frequency vs meridional wavenumber, and this is shown in Figure 3(b). The spectra are averaged over a longitudinal band of $89.625^{\circ} \mathrm{E}$ $90.625^{\circ} \mathrm{E}$ (where we have the largest latitudinal extent of the Bay). The meridional wavenumber has been normalized by the longitudinal cross-section of $\mathrm{BoB}$ which is equal to 1675 $\mathrm{km}\left(67 \times 1 / 4^{\circ}\right)$ at $90^{\circ} \mathrm{E}$. We note that the most of the power is distributed between $\left|k_{x}\right| \approx 1-5$, with a maximum between $1<\left|k_{y}\right|<2$. Also, power appears to be distributed asymmetrically, higher in the northward direction than southwards. Both the wavenumber-frequency plots, $\sigma-k_{x}$ and $\sigma-k_{y}$, have largest power in the temporal band of 60-90 days.

Finally, power spectra are examined to get an idea of the energy associated with the different length and time scales in the geostrophic velocity field. Specifically, we compute kinetic energy spectra and average over $11.125^{\circ} \mathrm{N}$ to $12.125^{\circ} \mathrm{N}$ which resolves largest zonal scales in the Bay. In a similar manner, spectra for meridional wavenumber have been averaged over $89.675^{\circ} \mathrm{E}$ to $90.675^{\circ} \mathrm{E}$ (again, these particular longitudes are chosen to resolve the largest meridional scales in the Bay). The slopes of the spectra, as seen in the first panel of Figure 4(a), are all close to a -3 power-law between approximately $100 \mathrm{~km}$ and $250 \mathrm{~km}$ in both the zonal and meridional directions. This is agreement with a forward enstrophy cascading regime of surface geostrophic currents from about 200 $\mathrm{km}$ to $100 \mathrm{~km}$ in the global open oceans [see, for example, the detailed discussion in 39]. The temporal spectrum is estimated by calculating the spectrum at each grid point and then averaging. This is done for each year and the results are presented in log-log and variance preserving form in the second and third panels of Figure 4, respectively. The variance preserving form, in agreement with the wavenumber-frequency plots, shows relatively isolated peaks at scales longer than 30 days. Further, the log-log plot shows signs of an approximate power-law, with a -3 exponent, for time scales that range from about 10-30 days. The match in temporal and spatial spectral exponents suggests that Taylor's hypothesis appears to hold at these scales; specifically, using an annual average speed of $0.2 \mathrm{~m} / \mathrm{s}$, a spatial scale of $200 \mathrm{~km}$ maps to approximately 10 days [see, for example, 31, 71]. Note that, given the approximate ten day frequency of repeat satellite passes in AVISO, periods below two weeks suffer from aliasing, and the spectra at these smaller timescales are likely to be unreliable [5]. Taken together, the spatial and temporal spectra suggest an uninterrupted distribution of power across mesoscales and from intraseasonal to weekly time scales, respectively. 


\section{MIXING OF PASSIVE TRACERS}

As demonstrated, geostrophic flow in the BoB has a multiscale character in both space and time. Specifically, there is strong seasonal dependence of the surface flow [for example, current disruption and reversal, 66, 77], along with significant subseasonal variability consisting of geostrophically balanced disturbances that exhibit predominantly westward phase speeds and align quite well with the dispersion curves for baroclinic Rossby waves. All together, the flow provides a rich playground for the mixing of passive fields. As it happens, aperiodic Rossby waves by themselves have been examined in detail as idealized models of chaotic mixing [see, for example, 56]. The principal tool used in these mixing calculations is the Lagrangian advection of parcels. This is done using a Runge Kutta fourth order (RK4) scheme. Further, given that the data is on a fixed grid, the flow has been interpolated by a bilinear interpolation scheme.

As our measures of mixing are Lagrangian in nature, it is worth identifying the limits imposed on the calculations due to the resolution of the altimeter data. In general, as discussed by [12], coarse velocity field data performs satisfactorily with regard to passive advection when its kinetic energy spectrum follows a -3 power-law. Of course, finer scale data can improve quantification of Lagrangian measures [15]. As seen in Figure 4(a), currents in the Bay follow this scaling over a range of approximately 100 to $250 \mathrm{~km}$. But, the situation is complicated at smaller scales. Specifically, at the ocean's surface, scales below approximately $100 \mathrm{~km}$ (depending on the region in consideration) have a significant contribution from the divergent component of the flow [18, 19, 21, 63], and spectra at these scales smaller also show signs of flattening to shallower power-laws [20]. Not only is the altimeter derived geostrophic data attenuated by filtering below scales of approximately $100 \mathrm{~km}$ [see, for example, 6, 29], it is unlikely to be a dominant contributor to the actual surface currents. Thus, caution must be exercised in interpreting Lagrangian measures computed from purely geostrophic data below a scale of approximately $100 \mathrm{~km}$.

\section{A. A Sign of Chaos}

We begin with a simple numerical experiment where the BoB is divided into zonal and longitudinal sections. Each band is approximately $2^{\circ}$ wide and is identified by a separate color as seen in the first two panels of Figure 5. Parcels in each band retain their color and are advected for about six weeks. Such experiments give a basic feel for the mixing processes at work [see, for example, 57]. Snapshots of the scalar field are shown every two weeks in Figure 5. We notice that within the first two weeks, the bands are distorted and form extended filaments and whorls. In fact, the boundaries between the different colors evolve towards highly complicated contours. This process continues with the repeated wrapping around of progressively thinner scalar filaments, i.e., a cas- cade of tracer variance to small scales. Indeed, the geometric picture that emerges is that of chaotic advection of a tracer field [54], and by week six it is quite difficult to distinguish between the longitudinal and latitudinal bands. With this qualitative picture in mind, we now proceed to more quantitative measures of mixing in the BoB.

\section{B. Finite Time Lyapunov Exponents}

A fundamental quantitative characteristic of a chaotic flow is its Lyapunov exponent, this is defined as the exponential rate of separation, averaged over infinite time, of fluid parcels with initial infinitesimal separation [13]. For practical problems, the limit of time tending to $\infty$ is not feasible, and the notion is generalized to the so-called Finite Time Lyapunov Exponents (FTLE, $\lambda_{T}$ ). Specifically,

$$
\lambda_{T}(\tau)=\lim _{r(0) \rightarrow 0} \frac{1}{\tau} \log \frac{r(\tau)}{r(0)} .
$$

For non-autonomous flows, the FTLE is essentially a measure of integrated strain along a parcel's trajectory. Here, $\lambda_{T}(\tau)$ is calculated from the logarithm of the largest eigenvalue of $M^{T} M$, where $M$ is the deformation matrix obtained by integrating the Jacobian of the flow along a trajectory [details can be found in, 3, 34, 79]. A finite difference scheme is employed to compute the Jacobian and its traceless component is used to obtain $M$, which ensures that $\lambda_{T}(\tau)$ is positive.

FTLEs are estimated for $\tau=5,10,15$ and 20 days for all the months of four years. Proceeding seasonally, we have averaged FTLEs for Feb-Mar-Apr (FMA), Jun-Jul-Aug-Sep (JJAS) and Oct-Nov-Dec (OND). Further, the average is for seasons from all four years of data (2010-2013). Figure 6 shows the resulting seasonal FTLE maps for $\tau=5$ and 10 days. Positive values of the FTLE indicate chaotic behavior over most regions of the Bay. In the premonsoon season (FMA), the FTLEs after 5 and 10 days are high along the western boundary and the northern Bay with values of approximately $0.15-0.3 d a y^{-1}$ and 0.1-0.2 $d a y^{-1}$, respectively. Interestingly, for $\tau=10$ days, the southwest portion of the Bay (near the Andaman Sea) also shows strong chaotic mixing. The picture changes in the monsoon period (JJAS), with higher FTLEs on the western boundary moving systematically equatorward. Another notable feature of JJAS is the emergence of a localized pocket of high FTLEs off the east coast of Sri Lanka, this enhanced mixing during the monsoon is due to the so-called Sri Lankan dome [76]. Further, the central regions of the Bay show relatively smaller FTLEs, suggestive of kinematic barriers to basin wide mixing between the eastern and western portions of the Bay. This is consistent with Figure 5 where we saw stretching and folding at scales smaller than the basin size. Finally, in OND, the southern part of the Bay lights up with high FTLEs. A close inspection of the maps in OND shows signs of a ring of high FTLEs between $85^{\circ}-90^{\circ} \mathrm{E}$ and $8^{\circ}-12^{\circ} \mathrm{N}$, a feature sometimes referred to as the 
BoB dome [76]. The northwest boundary is now relatively quiescent with low FTLE values. Overall, we see a seasonal cycle in mixing with rapid stirring progressively moving from the northern to southern Bay, from pre-monsoonal to postmonsoonal periods, respectively. Further, the eddy kinetic energy (EKE) in the Bay (where eddies are defined as deviations from a climatological 4 year mean) in each season is also shown in the third panel of Figure 6. Clearly, the EKE map aligns quite closely with that of the FTLEs in each season. This has been noted on global [78], as well more local scales [79], in the world's oceans.

At a fundamental level, the action of a chaotic flow on the transport or evolution of a passive field requires a knowledge of the probability density function of the FTLEs [see, for example, 11, 30, 35, 73]. The histogram of FTLEs is shown in the first panel of Figure 7. This distribution reflects the spatially non-uniform nature of stirring induced by the geostrophic currents in the Bay. Indeed, the slow right tail represents regions that experience rapid mixing, while the left tail is indicative of slow rates of stirring. Also, the shape of the distribution changes for different $\tau$. Specifically, the histogram becomes taller (mean decreases) with more of a stretched exponential tail for larger $\tau$. In essence, the nonuniformity of mixing is highlighted more starkly for longer time intervals. Even though the regions of strong mixing vary from season to season, as seen in the second panel of Figure 7, there is not much of a seasonal dependence in the FTLE distributions, i.e., the Bay is non-uniformly chaotic throughout the year. This can also be seen in Figure7(c), which shows a daily time series of the mean FTLE over the Bay through the year. The average stirring rate is quite uniform through the year, though there is a marginal increase during the post monsoonal months.

For consistency with other parts of the world's oceans $[78,80]$, we note that a Weibull distribution (shown in the fourth panel of Figure 7) accurately fits the FTLE histogram normalized by the mean FTLE. The specific expression plotted in Figure 7(d) is,

$$
P(\lambda)=\frac{b}{a}\left(\frac{\lambda}{a}\right)^{b-1} \exp \left(-\frac{\lambda^{b}}{a^{b}}\right),
$$

with $a=1.15$ and $b=1.95$.

\section{Relative Dispersion}

Another commonly used mixing diagnostic is relative dispersion [RD; see for example, 42]. This is defined as,

$$
\left\langle R^{2}(t)\right\rangle=\frac{1}{N(N-1)} \sum_{i \neq j} R^{2}{ }_{i j}(t)
$$

where, $\left\langle R^{2}(t)\right\rangle$ is the mean relative dispersion of an ensemble of $N$ pairs having the same initial separation with ran- dom orientation. $\mathrm{RD}$, along with notions such as normal or anomalous diffusion, helps in quantifying the homogenization of tracers [see, for example, 43, 72, 81, for ideal, oceanic and atmospheric applications, respectively]. Recently, [80] have compared RD and FTLEs, and highlighted how they explore different aspects of the mixing process. Quite starkly, even in the case when the FTLE distribution collapses to a single point, the RD exhibits a wide spread [80].

In practice, we advected 1000 pairs of parcels at a given grid location for 90 days starting on the first day of each month in all the four years. Two suites of experiments were conducted with pairs in a circle that are initially 10 and $25 \mathrm{~km}$ apart, respectively. The evolution of RD with these two initial separations is shown in Figure 8(a) and 8(b). At small scales, the advecting flow is a smoothly interpolated geostrophic flow, hence the observed exponential separation is not surprising. As discussed earlier, at small scales (below approximately $100 \mathrm{~km}$, depending on the region in consideration), the surface ocean flow appears to have a relatively shallow kinetic energy spectrum [20], and a significant divergent component $[18,21,63]$. In fact, pair separation on the order of a few $\mathrm{km}$, estimated using drifter data from the Gulf of Mexico, appears to conform with the classic Richardson $\left\langle R^{2}\right\rangle \sim t^{3}$ prescription [60]. Indeed, it would be interesting to ascertain the behavior of $\mathrm{RD}$ in the 10-100 $\mathrm{km}$ range via high resolution surface ocean models.

At scales between 100 and $250 \mathrm{~km}$, we observe that the $\mathrm{RD}$ is reasonably well approximated by a power-law growth in time. While we anticipate exponential separation in an enstrophy cascading regime, it should be remembered that this is under the assumption of an inertial range with a constant enstrophy flux [47]. Computation of the enstrophy flux using altimeter data does show a dominant forward enstrophy regime at these scales, but the enstrophy flux is not constant, and is actually scale dependent [39]. Therefore, the powerlaw growth of RD is not inconsistent with a forward enstrophy transfer regime. Finally, at scales larger than $250 \mathrm{~km}$, the growth of RD slows down and tends to $\left\langle R^{2}\right\rangle \sim t$, indicative of eddy diffusive behavior. This is seen in the emergent flat portion of a compensated RD plot (for the $25 \mathrm{~km}$ initial separation case) beyond approximately 70 days of evolution as shown in Figure 8(c).

As with the FTLEs, the distribution of RD at a given time is of importance in assessing the non-uniformity of mixing. The distribution of RD (actually, the square root of RD, normalized by its rms value), at various times, when the mean square root RD lies between 100 and $250 \mathrm{~km}$ is shown in Figure 8(d) and 8(e) for 10 and $25 \mathrm{~km}$ initial separations, respectively. Quite clearly, the distributions are not Gaussian, rather they show signs of a log-normal behavior. Spatial maps of the mean RD are presented in Figure IV C. In the premonsoon period (FMA), the western coastline supports rapid pair dispersal, while the southern Bay shows subdued RD values. In the monsoon season (JJAS), high RD shifts slightly off the western coast, and in addition, rapid dispersion picks up in the parts of the southern and eastern Bay. Finally, in the postmonsoon period (OND), along with the west coast, much of 
the southern and eastern Bay lights up with high RD values. Interestingly, all through the year, the central Bay is characterized by low RD values, and this also points to a local or eddy scale mixing, rather than basin wide homogenization.

\section{Finite Size Lyapunov Exponent}

For a flow with multiple scales, such as that in the BoB, the Finite Size Lyapunov Exponent (FSLE) is a convenient measure that quantifies the chaotic nature of the flow $[9,36]$. In particular, the FLSE allows one to estimate the scale up to which mixing is chaotic, and beyond which, a diffusive framework is appropriate. From a practical viewpoint, this also allows an estimation of a scale dependent diffusion coefficient [44].

Following [33], a set of $M$ tracers with some initial distribution and standard deviation $\sigma$ are followed in time as they are transported by the velocity field. The parameter $\sigma(t)$ is defined as,

$$
\begin{gathered}
\sigma(t)=\left\langle\left|x_{i}(t)-\left\langle x_{i}(t)\right\rangle\right|^{2}\right\rangle^{1 / 2}, \text { where, } \\
\left\langle x_{i}(t)\right\rangle \equiv\left\langle\left\{x_{i}(t): i=1,2, \ldots M\right\}\right\rangle=\frac{1}{M} \sum_{i=1}^{M} x_{i}(t) .
\end{gathered}
$$

We define the initial size of the cluster $\sigma_{0}$ according to 5 and 6 , and measure the time $T\left(\sigma_{0}, \mathrm{r}\right)$ it takes for the growth from $\sigma_{0}$ to $\sigma_{1}=\mathrm{r} \sigma_{0}, T\left(\sigma_{1}, r\right)$ the time it takes for the growth from $\sigma_{1}$ to $\sigma_{2}=\mathrm{r} \sigma_{1}$, and so on up to the largest scale under consideration (the sub-basin scale). A set of $N$ experiments is then performed with different initial conditions for the cluster of particles $N \gg 1$, and we calculate the mean time $\tau$ that a cluster with size $\sigma_{j}$ takes to grow by a factor $r$ and the $\langle\cdot\rangle$ operation is the average over the tracer ensemble. This reads,

$$
\tau\left(\sigma_{j}, r\right)=\left\langle T\left(\sigma_{j}, r\right)\right\rangle=\frac{1}{N} \sum_{j=1}^{N} T\left(\sigma_{j}, r\right)
$$

The FSLE parameter as a function of the scale is then obtained by the following expression,

$$
\lambda\left(x, \sigma_{j}\right)=\frac{\log r}{\tau\left(\sigma_{j}, r\right)},
$$

which is not sensitive to variations in $r$ when it is close to $1+$. From the FSLE, we define the Finite Size Diffusion Coefficient (FSDC, D) as,

$$
D(\sigma)=\sigma^{2} \lambda(\sigma)
$$

As the cluster size grows, if it is driven by chaos at very small scales $\left(\ll l_{u}\right)$ and by (eddy) diffusion at very large scales $\left(\gg l_{u}\right)$, then $\lambda(\sigma)$ has the following asymptotic behavior,

$$
\lambda(\sigma)= \begin{cases}\lambda_{\max }, & \text { if } \sigma \ll l_{u}, \\ \frac{D}{\sigma^{2}}, & \text { if } \sigma \gg l_{u} .\end{cases}
$$

Though, for real world data, as demonstrated in [28] in an oceanic setting, there usually exist other intermediate regimes for $\lambda(\sigma)$.

Practically, for calculating the FSLE, a cluster with 10000 parcels was released at each grid location, and these were advected in time for approximately 60 days. In fact, we have chosen a cluster whose initial standard deviation is $25 \mathrm{~km}$ and followed the parcels till the standard deviation increases by a factor of 1.2. The size of the initial cluster is varied from 25 $\mathrm{km}$ to approximately $300 \mathrm{~km}$. This experiment was repeated for every year, and an average was taken over all years.

The behavior of the FSLE with cluster size can be seen in Figure 10(a). As with RD, the smoothly interpolated flow results in an exponential separation, i.e., a relatively flat FSLE, for scales below approximately $100 \mathrm{~km}$. For the NB and SB an eddy-diffusive regime is observed for scales greater than 200-250 $\mathrm{km}$ (via a -2 scaling of the FSLE in Figure 10(a)). At intermediate scales, i.e., 100 to $250 \mathrm{~km}$, the FSLE transitions between these two end regimes. The behavior of the Andaman Sea region is somewhat different with the diffusive regime emerging earlier between 150 and $200 \mathrm{~km}$, itself. This overall picture is consistent with the calculated "eddy length scale" and the local chaotic mixing seen in Figure IV C. Interestingly, the CB is quite distinct in that the FSLE never really transitions to an eddy-diffusive regime. It is possible that, especially in the intermediate regime, finer data may yield different power-laws as seen by [28] in other parts of the world's oceans. An estimation of a scale dependent diffusion co-efficient, the FSDC, is presented in Figure 10(b). It is interesting to note that the FSDC scales as a power-law with cluster size (exponent of 1.73), this is potentially a useful reference which provides a resolution-diffusivity relation for use in models. At large scales, for the NB and SB, the eddy diffusivity is approximately $10^{4} \mathrm{~m}^{2} / \mathrm{s}$. In the Andaman Sea region, the value is lower and is near $6 \times 10^{3} \mathrm{~m}^{2} / \mathrm{s}$. These numbers are higher (by a factor of 2) than the minimum OsbornCox eddy diffusivity estimates as determined by [1] (see in particular the Bay of Bengal in their global Figure 5), but are of the same order as diffusivities estimated via FSLEs in other parts of the world's oceans [28].

The seasonal mean picture of FSLEs (within the chaotic regime) is shown in Figure 11. As with the seasonal picture from the FTLEs, high values of the FSLE show equatorward movement from FMA, through JJAS into OND. Note that the mouth of the river Ganga-Brahmaputra basin and Irrawaddy catchment area show high FSLE in JJAS and OND season. Signs of the Sri Lankan and BoB domes can also be seen in the FSLE maps in JJAS and OND, respectively. Also, low 
FSLE values can be seen in the CB region throughout the year which are consistent with a partition that inhibits basin scale mixing.

\section{ANALYSIS OF A SINGLE FRESH WATER MIXING EVENT}

As mentioned earlier, a significant amount of surface fresh water enters the Bay in the postmonsoon season from the Ganga-Brahmaputra (GB) catchment [22, 55], and plays an important role in its surface salinity budget [38]. This inflow from GB progresses southward and is largely confined to the western side of the Bay [referred to as a river in the sea, 22]. The fate of this fresh water, including its advection, and homogenization with a more salty environment has been analyzed in detail [4]. Indeed, it appears that the fresh water maintains its identity for an extended period and finally extended tongues become saltier in the southern Bay [4, 14]. Lagrangian salinity change maps from data from August to October of 2013 also show an increase in the saltiness with southward advection [49]. Though it should be kept in mind that some fresh water retains its identify for a prolonged period and its transport to remote regions in the Indian Ocean has been documented [67].

Taking advantage of satellite data from 2015, stirring of the salinity field by eddies in the postmonsoon season has been recently explored by [32]. Here, we highlight role of eddies off the eastern coast on India in preserving the identity of fresh water. In particular, we showcase a particular eddy that formed around the end of October and lasted to the end of November in 2015. The salinity field along with quivers of the geostrophic flow on October 25 are shown in the first panel of Figure 12(a). The eddy is well formed and spans the approximate region $16-19^{\circ} \mathrm{N}$ to $85-88^{\circ} \mathrm{E}$, with a slight northwestsoutheast tilt. The second panel of Figure 12(a) shows a passive tracer initialized to have the same value as the salinity field, along with contours of 5 day FTLEs. Note that a fair amount of fresh water (blue) is contained within the eddy. The two panels of Figure 12(b) show maps of FTLEs (15 day) and FSLEs $(r=1.2)$ in this part of the Bay. Quite clearly, the region inside the eddy is characterized by relatively low FTLEs/FSLEs while it is surrounded by a high FTLE/FSLE ring. Also, note that inside the eddy, the interior rim has lowest FTLEs while the central region has relatively higher stirring rates. Thus, much like the scenario described by [64], we expect a tracer to be well mixed within an eddy, but not communicate significantly (or, possibly on a slower timescale) with the "external" Bay.

Fifteen days later, as seen in the first panel of Figure 13(a), low salinity water is retained within the eddy. The passive tracer, advected via the geostrophic flow in these fifteen days is shown in the second panel of Figure 13(a). While the bulk of "fresh" passive tracer is in the eddy, long filaments that initially comprised of material localized on the outer side of the eddy, extend southwards up to $12^{\circ} \mathrm{N}$ and westward to the coast. These narrow filaments are not seen in the actual salin- ity field, and have most likely been homogenized via the more salty environment - possibly due to strong vertical mixing [4, 14]. Finally, another fifteen days later, on November 24 (Figure 13(b)), the passive and salinity fields compare favorably, even though the eddy itself has deformed considerably. In fact, it is now squeezed along the coast into a northeastsouthwest orientation, and fresh water begins to be strained out of its southwest boundary. Remnants of ejected filaments from the edges of the eddy that are seen in the passive field are absent in the salinity data, presumably also having being been homogenized to more salty levels.

Thus, in this period of one month, fresh water trapped inside the eddy is shielded by means of kinematic transport barriers that are clearly delineated by the FTLE and FSLE maps. In addition, this eddy trapped fresh water stays in place rather than being rapidly advected in a southward direction. On comparison with the passive tracer, we note that ejected passive filaments are not seen in the fresh water signature, thus highlighting the role of the kinematic barriers in the preservation of fresh water on this monthly timescale.

\section{SUMMARY AND DISCUSSION}

Using surface geostrophic currents derived from altimetry data, we studied mixing along the surface of the Bay of Bengal. In particular, our primary focus was on mixing that takes place on intraseasonal scales. To begin with, we examined the flow by means of Hovmöller plots and wavenumber-frequency diagrams. It was seen that the geostrophic currents in the Bay are dominated by westward progressing disturbances that have temporal scales between 50 and 100 days. In fact, the power in these systems aligned well with the theoretical dispersion curves for linear baroclinic Rossby waves. Interestingly, some of these have length scales that are smaller than the local deformation scale, and show an eastward group velocity which was noted in the Hovmöller plots. Temporal and spatial power spectra were seen to follow approximate powerlaws (-3 scaling, from 100-250 km and 10-30 days, respectively) and suggested an uninterrupted distribution of power across length and subseasonal time scales.

The advection of latitudinal and longitudinal bands by the multiscale geostrophic flow immediately hinted at the presence of chaotic mixing. In particular, the repeated folding and filamentation of stripes brought forth a complicated geometry to the mixing process, and by the end of approximately six weeks, it was difficult to distinguish between the two initial conditions. In addition, mixing was not basin wide but was seen to be restricted to the scale of eddies.

A more quantitative measure of mixing was provided by the FTLEs. Maps of the FTLEs suggested an equatorward movement of regions of enhanced mixing from pre-monsoonal to post-monsoonal periods. In each season, the central Bay had low FTLE values, suggestive of the presence of kinematic barriers that were consistent with the eddy scale of mixing noted above. Specific seasonal features, such as the appearance of 
the Sri Lankan dome in the monsoon, were captured by high FTLE pockets. Also, overall, the spatial maps of FTLEs were in tune with those of eddy kinetic energy. Variations in FTLEs are known to be important in determining the outcome of advection-diffusion on passive fields; here, the non-uniform nature of surface mixing in the Bay was manifest in the histograms of FTLEs that had long tails and their shape, and as in other parts of the world's oceans, was captured well by a Weibull distribution. In terms of a domain average, the FTLE for a week's increment was approximately $0.1 d^{-1} y^{-1}$, while the spread captured by the histogram ranged up to $0.5 \mathrm{day}^{-1}$. In addition, with longer time increments, the distribution of FTLEs became taller (and smaller mean), but with progressively more stretched exponential like tails. Thus, the nonuniformity of mixing was further highlighted at longer time intervals.

The relative dispersion (RD) of parcels provided a complimentary view to the FTLEs. Below $100 \mathrm{~km}$, the smoothly interpolated nature of the data results in pair separation that was exponential in time. From 100 to $250 \mathrm{~km}$, i.e., the RD followed a power-law in time, which is consistent a forward enstrophy transfer regime, but with a variable enstrophy flux. At larger scales, the pair separation took on an eddy-diffusive growth, i.e., $\left\langle R^{2}\right\rangle \sim t$. Consistent with the FTLEs, seasonal mean maps showed a southward progression of high RD, and a suppressed dispersion in the central Bay throughout the year.

FSLEs were then estimated for the Bay, these provide a quantitative measure of the scale up to which tracers experience chaotic mixing. Averaging the growth of clusters in different months, and across all four years, the FSLE followed theoretical expectations. In particular, the FTLE was relatively constant (up to $100 \mathrm{~km}$ ), transitions (from 100 to $250 \mathrm{~km}$ ) and then enters an eddy-diffusive regime (above 250 $\mathrm{km}$ ). The Andaman Sea was seen to enter an eddy-diffusive regime at relatively smaller scales $(150 \mathrm{~km})$ while the central showed no signs of this transition. Overall, in agreement with FTLEs and latitudinal (longitudinal) stripe experiments, chaotic mixing takes place within eddies. Beyond the eddy scale, the -2 power-law suggested an eddy diffusive behavior (except in the central Bay), with each eddy acting independently and inducing a random walk of the tracer. The large scale eddy-diffusivity estimated from the FSLE plots was about $10^{4} \mathrm{~m}^{2} / \mathrm{s}$ in the northern and southern Bay, and approximately $6 \times 10^{3} \mathrm{~m}^{2} / \mathrm{s}$ in the Andaman Sea region. Interestingly, before the emergence of an eddy-diffusive regime, the finite size diffusion coefficient showed a similar powerlaw behavior in all regions of the Bay (exponent of 1.73 with cluster size). These estimates can be used as a guideline for ocean models, being run at a given resolution, that hope to capture the stirring at the surface of the Bay in an accurate manner.

Finally, from a global perspective of mixing in the Bay, we moved to the analysis of a single fresh water mixing episode. Guided by satellite salinity data in 2015 , we demonstrated how an eddy in the western Bay helps preserve the identity of post-monsoonal fresh water from the Ganga-Brahmaputra river mouth. In particular, FSLE and FTLE maps clearly delineated kinematic boundaries that aid in mixing within eddies, but prevent the intermingling of fresh water within an eddy with the saltier external Bay over the timescale of a month. Thus, while eddies stir the salinity field on a large scale, they also help maintain the freshness of water trapped within themselves.

\section{ACKNOWLEDGEMENT}

The authors would like to thank AVISO and JPL for making MADT-H-UV and SMAP salinity data freely available. The authors would like to express their gratitude to Dr. Debasis Sengupta, Dr. Anirban Guha and Dr. Amit Tandon for helpful discussions and technical advice. We also thank the Divecha Centre for Climate Change, IISc for financial support.
[1] R. Abernathey and J. Marshall. Global surface eddy diffusivities derived from satellite altimetry. Journal of Geophysical Research, 118:901-916, 2013. doi: 10.1002/jgrc.20066.

[2] E. Abraham. The generation of plankton patchiness by turbulent stirring. Nature, 391:577-580, 1998.

[3] E. R. Abraham and M. M. Bowen. Chaotic stirring by a mesoscale surface-ocean flow. Chaos: An Interdisciplinary Journal of Nonlinear Science, 12(2):373-381, 2002.

[4] V. Akhil et al. A modeling study of the processes of surface salinity seasonal cycle in the Bay of Bengal. Journal of Geophysical Research, 119(6):3926-3947, 2014. doi: 10.1002/2013JC009632.

[5] B. Arbic, R. Scott, G. Flierl, A. Morten, J. Richman, and J. Shriver. Nonlinear cascades of surface oceanic geostrophic kinetic energy in the frequency domain. Journal of Physical Oceanography, 42:1577-1600, 2012. doi: 10.1175/JPO-D-11-0151.1.

[6] B. K. Arbic, K. L. Polzin, R. B. Scott, J. G. Richman, and J. F. Shriver. On eddy viscosity, energy cascades, and the horizontal resolution of gridded satellite altimeter products. Journal of Physical Oceanography, 43(2):283-300, 2013. doi: 10.1175/JPO-D-11-0240.1.

[7] H. Aref. Stirring by chaotic advection. Journal of Fluid Mechanics,
143:1-21, 1984.

[8] H. Aref et al. Frontiers of chaotic advection. Reviews of Modern Physics, 89, 2017. doi: 10.1103/RevModPhys.89.025007.

[9] V. Artale, G. Boffetta, A. Celani, M. Cencini, and A. Vulpiani. Dispersion of passive tracers in closed basins: Beyond the diffusion coefficient. Physics of Fluids, 11:3162-3171, 1997.

[10] M. Babu, Y. Sarma, V. Murty, and P. Vethamony. On the circulation in the Bay of Bengal during northern spring inter-monsoon (March-April 1987). Deep Sea Research Part II: Topical Studies in Oceanography, 50 (5):855-865, 2003.

[11] E. Balkovsky and A. Fouxon. Universal long-time properties of Lagrangian statistics in the Batchelor regime and their application to the passive scalar problem. Physical Review E, 60(4):4164, 1999.

[12] P. Bartello. Using low-resolution winds to deduce fine structure in tracers. Atmosphere-Ocean, 38:303-320, 2000. doi: 10.1080/07055900. 2000.9649650.

[13] G. Benettin, L. Galgani, A. Giorgilli, and J.-M. Strelcyn. Lyapunov characteristic exponents for smooth dynamical systems and for Hamiltonian systems; a method for computing all of them. Part 1: Theory. Meccanica, 15(1):9-20, 1980. 
[14] R. Benshila et al. The upper Bay of Bengal salinity structure in a highresolution model. Ocean Modelling, 74:36-52, 2014. doi: 10.1016/j. ocemod.2013.12.001.

[15] F. Beron-Vera. Mixing by low-and high-resolution surface geostrophic currents. Journal of Geophysical Research, 115:C10027, 2010. doi: 10.1029/2009JC006006.

[16] F. Beron-Vera, M. Olascoaga, and G. Goni. Oceanic mesoscale eddies as revealed by Lagrangian coherent structures. Geophysical Research Letters, 35:L12603, 2008. doi: 0.1029/2008GL033957.

[17] G. Boffetta et al. Detecting barriers to transport: a review of different techniques. Physica D, 159:58-70, 2001.

[18] O. Bühler, J. Callies, and R. Ferrari. Wave-vortex decomposition of one-dimensional ship-track data. J. Fluid Mech., 756:1007-1026, 2014. doi: $10.1017 / \mathrm{jfm} .2014 .488$.

[19] O. Bühler, M. Kuang, and E. Tabak. Anisotropic helmholtz and wavevortex decomposition of one-dimensional spectra. J. Fluid Mech., 815: 361-387, 2017. doi: 10.1017/jfm.2017.57.

[20] J. Callies and R. Ferrari. Interpreting energy and tracer spectra of upper-ocean turbulence in the submesoscale range $(1-200 \mathrm{~km})$. Journal of Physical Oceanography, 43(11):2456-2474, 2013. doi: 10.1175/ JPO-D-13-063.1.

[21] X. Capet, J. McWilliams, M. Molemaker, and A. Shchepetkin. Mesoscale to submesoscale transition in the California current system. Part III: Energy balance and flux. Journal of Physical Oceanography, 38(10):2256-2269, 2008. doi: 10.1175/2008JPO3810.1.

[22] A. Chaitanya, M. Lengaigne, J. Vialard, V. Gopalakrishna, F. Durand, C. Kranthikumar, C. Amritash, V. Suneel, F. Papa, and M. Ravichandran. Salinity Measurements Collected by Fishermen Reveal a "River in the Sea" Flowing Along the Eastern Coast of India. BAMS, pages 1897-1908, 2014. doi: 10.1175/BAMS-D-12-00243.1.

[23] D. Chelton, M. Schlax, R. Samelson, and R. de Szoeke. Global observations of large oceanic eddies. Geophysical Research Letters, 34: L15606, 2007. doi: 10.1029/2007GL030812.

[24] D. B. Chelton, R. A. Deszoeke, M. G. Schlax, K. El Naggar, and N. Siwertz. Geographical variability of the first baroclinic rossby radius of deformation. Journal of Physical Oceanography, 28(3):433-460, 1998.

[25] G. Chen, D. Wang, and Y. Hou. The features and interannual variability mechanism of mesoscale eddies in the Bay of Bengal. Continental Shelf Research, 47:178-185, 2012.

[26] X. Cheng, S.-P. Xie, J. McCreary, Y. Qi, and Y. Du. Intraseasonal variability of sea surface height in the Bay of Bengal. Journal of Geophysical Research: Oceans, 118(2):816-830, 2013.

[27] M. Chertkov. On how a joint interaction of two innocent partners (smooth advection and linear damping) produces a strong intermittency. Physics of Fluids, 10(11):3017-3019, 1998.

[28] R. Corrado, G. Lacorata, L. Palatella, R. Santoleri, and E. Zambianchi. General characteristics of relative dispersion in the ocean. Scientific Reports, 7:46291, 2017. doi: 10.1038/srep46291.

[29] C. Dufau et al. Mesoscale resolution capability of altimetry: Present and future. Journal of Geophysical Research, 121:4910-4927, 2016. doi: 10.1002/2015JC010904.

[30] D. Fereday and P. Haynes. Scalar decay in two-dimensional chaotic advection and Batchelor-regime turbulence. Physics of Fluids, 16(12): 4359-4370, 2004.

[31] R. Ferrari and C. Wunsch. The distribution of eddy kinetic and potential energies in the global ocean. Tellus, 62A:92, 2010.

[32] S. Fournier et al. Modulation of the Ganges-Brahmaputra River Plume by the Indian Ocean Dipole and Eddies Inferred From Satellite Observations. Journal of Geophysical Research, 122:9591-9604, 2017. doi: 10.1002/2017JC013333.

[33] A. García-Olivares, J. Isern-Fontanet, and E. García-Ladona. Dispersion of passive tracers and finite-scale Lyapunov exponents in the Western Mediterranean Sea. Deep Sea Research Part I: Oceanographic Research Papers, 54(2):253-268, 2007.

[34] G. Haller. Lagrangian coherent structures from approximate velocity data. Physics of Fluids, 14(6):1851-1861, 2002.

[35] P. Haynes and J. Vanneste. Stratospheric tracer spectra. Journal of the Atmospheric Sciences, 61:161-178, 2004.
[36] I. Hernández-Carrasco, C. López, E. Hernández-García, and A. Turiel. How reliable are finite-size lyapunov exponents for the assessment of ocean dynamics? Ocean Modelling, 36(3):208-218, 2011.

[37] E. Hernandez-Garcia and C. Lopez. Sustained plankton blooms under open chaotic flows. Ecol. Complex, 1:253-259, 2004.

[38] S. Howden and R. Murtugudde. Effects of rives inputs into the Bay of Bengal. Journal of Geophysical Research, 106(C9):19825-19843, 2001.

[39] H. Khatri, J. Sukhatme, A. Kumar, and M. Verma. Surface ocean enstrophy, kinetic energy fluxes and spectra from satellite altimetry. Journal of Geophysical Research, 2018. doi: 10.1029/2017JC013516.

[40] P. D. Killworth, D. B. Chelton, and R. A. de Szoeke. The speed of observed and theoretical long extratropical planetary waves. Journal of Physical Oceanography, 27(9):1946-1966, 1997.

[41] P. Kurien, M. Ikeda, and V. K. Valsala. Mesoscale variability along the east coast of India in spring as revealed from satellite data and OGCM simulations. Journal of Oceanography, 66(2):273-289, 2010.

[42] J. LaCasce. Relative displacement probability distribution functions from balloons and drifters. Journal of Marine Research, 68:433-457, 2010.

[43] J. LaCasce and K. Speer. Lagrangian statistics in unforced barotropic flows. Journal of Marine Research, 57:245-274, 1999.

[44] G. Lacorata, E. Aurell, and A. Vulpiani. Drifter dispersion in the Adriatic Sea: Lagrangian data and chaotic model. Annales Geophysicae, 19: 121-129, 2001.

[45] S. Lebonnois, D. Toublanc, F. Hourdin, and P. Rannou. Seasonal Variations of Titan's Atmospheric Composition. Icarus, 152:384-406, 2001.

[46] F. Lekien, C. Coulliette, A. Mariano, E. Ryan, L. Shay, G. Haller, and J. Marsden. Pollution release tied to invariant manifolds: A case study for the coast of Florida. Physica D, 210:1-22, 2005. doi: j.physd.2005. 06.023 .

[47] J. Lin. Relative dispersion in the enstrophy cascading inertial range of homogeneous two-dimensional turbulence. Journal of the Atmospheric Sciences, 29:394, 1972.

[48] A. Mahadevan and J. Campbell. Biogeochemical patchiness at the sea surface. Geophysical Research Letters, 29(19), 2002. doi: :10.1029/ 2001GL014116.

[49] A. Mahadevan, G. Spiro Jaeger, M. Freilich, M. Omand, E. Shroyer, and D. Sengupta. Freshwater in the Bay of Bengal: Its fate and role in air-sea heat exchange. Oceanography, 29:72-81, 2016.

[50] I. Mezic, S. Loire, V. Fonoberov, and P. Hogan. A new mixing diagnostic and gulf oil spill movement. Science, 330:486-489, 2010.

[51] Z. Neufeld, C. Lopez, E. Hernandez-Garcia, and O. Piro. Excitable media in open and closed chaotic flows. Physical Review E, 66:066208, 2002.

[52] M. Nuncio and S. P. Kumar. Life cycle of eddies along the western boundary of the Bay of Bengal and their implications. Journal of Marine Systems, 94:9-17, 2012.

[53] M. Olascoaga and G. Haller. Forecasting sudden changes in environmental pollution patterns. PNAS, 109:4738-4743, 2012. doi: pnas. 1118574109.

[54] J. Ottino. The Kinematics of Mixing, Stretching, Chaos and Transport. Cambrige University Press, 1989.

[55] F. Papa, S. K. Bala, R. K. Pandey, F. Durand, V. Gopalakrishna, A. Rahman, and W. B. Rossow. Ganga-Brahmaputra river discharge from Jason-2 radar altimetry: an update to the long-term satellite-derived estimates of continental freshwater forcing flux into the Bay of Bengal. Journal of Geophysical Research: Oceans, 117(C11), 2012. doi: 10.1029/2012JC008158.

[56] R. Pierrehumbert. Chaotic Mixing of Tracer and Vorticity by Modulated Travelling Rossby Waves. Geophysical and Astrophysical Fluid Dynamics, 58:285-319, 1991.

[57] R. Pierrehumbert and H. Yang. Global chaotic mixing on isentropic surfaces. Journal of the Atmospheric Sciences, 50(15):2462-2480, 1993.

[58] R. Pierrehumbert, H. Brogniez, and R. Roca. On the Relative Humidity of the Earth's Atmosphere. In The General Circulation of the Atmosphere. Princeton University Press, 2005.

[59] A. Poje and G. Haller. Geometry of cross-stream mixing in a double- 
gyre ocean model. Journal of Physical Oceanography, 29:1649-1665, 1999.

[60] A. Poje et al. Evidence of a forward energy cascade and Kolmogorov self-similarity in submesoscale ocean surface drifter observations. Physics of Fluids, 29:020701, 2017. doi: 10.1063/1.4974331.

[61] J. Potemra, M. Luther, and J. O'Brien. The seasonal circulation of the upper ocean in the Bay of Bengal. Journal of Geophysical Research, 96 (C7):12667-12683, 1991.

[62] S. Prants, M. Uleysky, and M. Budyansky. Lagrangian Oceanography: Large Scale Transport and Mixing Transport in the Ocean. Springer, 2017.

[63] B. Qiu, T. Nakano, S. Chen, and P. Klein. Submesoscale transition from geostrophic flows to internal waves in the northwestern $\mathrm{Pa}$ cific upper ocean. Nature Communications, (14055), 2017. doi: $10.1038 /$ ncomms 14055 .

[64] P. Rhines and W. Young. How rapidly is a passive scalar mixed within closed streamlines? Journal of Fluid Mechanics, 133:133-145, 1983.

[65] R. Samelson. Fluid exchange across a meandering jet. Journal of Physical Oceanography, 22:431-444, 1992.

[66] F. A. Schott and J. P. McCreary. The monsoon circulation of the Indian Ocean. Progress in Oceanography, 51(1):1-123, 2001.

[67] D. Sengupta, G. Bharath Raj, and S. Shenoi. Surface freshwater from Bay of Bengal runoff and Indonesian Throughflow in the tropical Indian Ocean. Geophysical Research Letters, 33:L22609, 2006.

[68] D. Sengupta, G. Bharath Raj, M. Ravichandran, J. Sree Lekha, and F. Papa. Near-surface salinity and stratification in the north Bay of Bengal from moored observations. Geophysical Research Letters, 43(9): 4448-4456, 2016.

[69] D. Shankar, J. McCreary, W. Han, and S. Shetye. Dynamics of the East India Coastal Current: 1. Analytic solutions forced by interior Ekman pumping and local alongshore winds. Journal of Geophysical Research: Oceans, 101(C6):13975-13991, 1996.

[70] D. Stammer. Global characteristics of ocean variability estimated from regional topex/poseidon altimeter measurements. Journal of Physical Oceanography, 27(8):1743-1769, 1997.

[71] D. Suhas and J. Sukhatme. Low frequency modulation of jets in quasigeostrophic turbulence. Physics of Fluids, 27:016601, 2015. doi: 10.1063/1.4905710.

[72] J. Sukhatme. Lagrangian velocity correlations and absolute dispersion in the midlatitude troposphere. Journal of the Atmospheric Sciences, 62: 3831-3836, 2005.

[73] J. Sukhatme and R. Pierrehumbert. Decay of passive scalars under the action of single scale smooth velocity fields in bounded twodimensional domains: From non-self-similar probability distribution functions to self-similar eigenmodes. Physical Review E, 66, 2002. doi: 10.1103/PhysRevE.66.056302.

[74] J. Sukhatme and W. R. Young. The advection-condensation model and water-vapour probability density functions. Quarterly Journal of the Royal Meteorological Society, 137(659):1561-1572, July 2011. ISSN 1477-870X. doi: 10.1002/qj.869.

[75] P. Vinayachandran and S. Mathew. Phytoplankton bloom in the Bay of Bengal during the northeast monsoon and its intensification by cyclones. Geophysical Research Letters, 30(11):1572, 2003. doi: 10.1029/2002GL016717.

[76] P. Vinayachandran and T. Yamagata. Monsoon Response of the Sea around Sri Lanka: Generation of Thermal Domes and Anticyclonic Vortices. Journal of Oceanography, 28:1946-1960, 1998.

[77] P. Vinayachandran, S. R. Shetye, D. Sengupta, and S. Gadgil. Forcing mechanisms of the Bay of Bengal circulation. Current Science, 71(10): 753-763, 1996.

[78] D. W. Waugh and E. R. Abraham. Stirring in the global surface ocean. Geophysical Research Letters, 35(20), 2008. doi: 10.1029/ 2008GL035526.

[79] D. W. Waugh, E. R. Abraham, and M. Bowen. Spatial variations of stirring in the surface ocean: A case study of the tasman sea. Journal of Physical Oceanography, 36:526-542, 2005. doi: 10.1175/JPO2865.1.

[80] D. W. Waugh, S. R. Keating, and M.-L. Chen. Diagnosing ocean stirring: Comparison of relative dispersion and finite-time lyapunov expo- nents. Journal of Physical Oceanography, 42(7):1173-1185, 2012.

[81] E. Weeks, J. Urbach, and H. Swinney. Anomalous diffusion on asymmetric random walks with a quasi-geostrophic flow example. Physica D, 97:291-310, 1996.

[82] J. Weiss and A. Provenzale. Transport and Mixing in Geophysical Flows. Springer, 2008.

[83] C. Wiggins. The Dynamical Systems Approach to Lagrangian Transport in Oceanic Flows. Annual Review of Fluid Mechanics, 37:295-328, 2005. doi: 10.1146/annurev.fluid.37.061903.175815.

[84] https://www.imarest.org/themarineprofessional/ item/3104-20-tonnes-of-oil-spilled-in-bay-of-bengal 


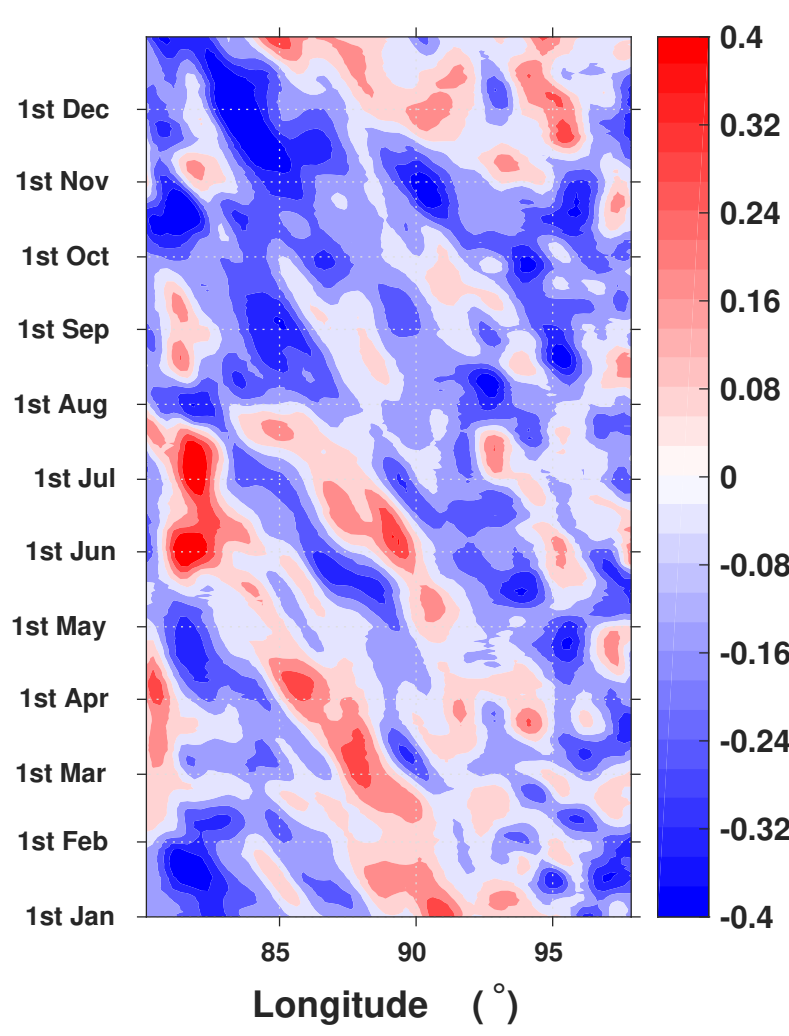

(a)

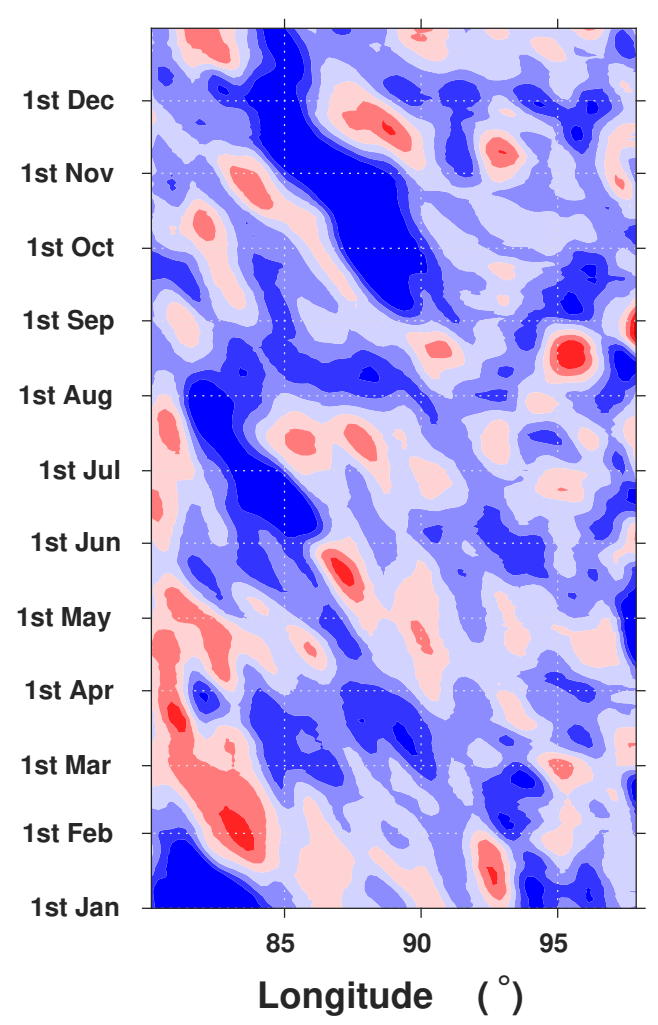

(c)

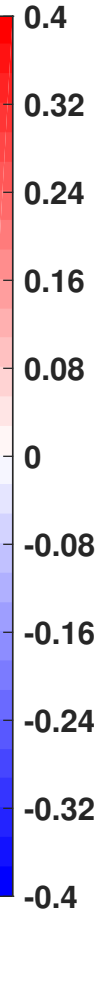

.16
0.24
-0.32

FIG. 2: Panels (a), (b), (c) and (d) show Hovmöller diagrams of the zonal geostrophic velocity in 2010, 2011, 2012 and 2013, respectively. The plots are from a longitude of $80^{\circ} \mathrm{E}$ to $100^{\circ} \mathrm{E}$ in the $\mathrm{BoB}$, the cross section is taken near the widest portion of the central Bay at $12.125^{\circ} \mathrm{N}$ 


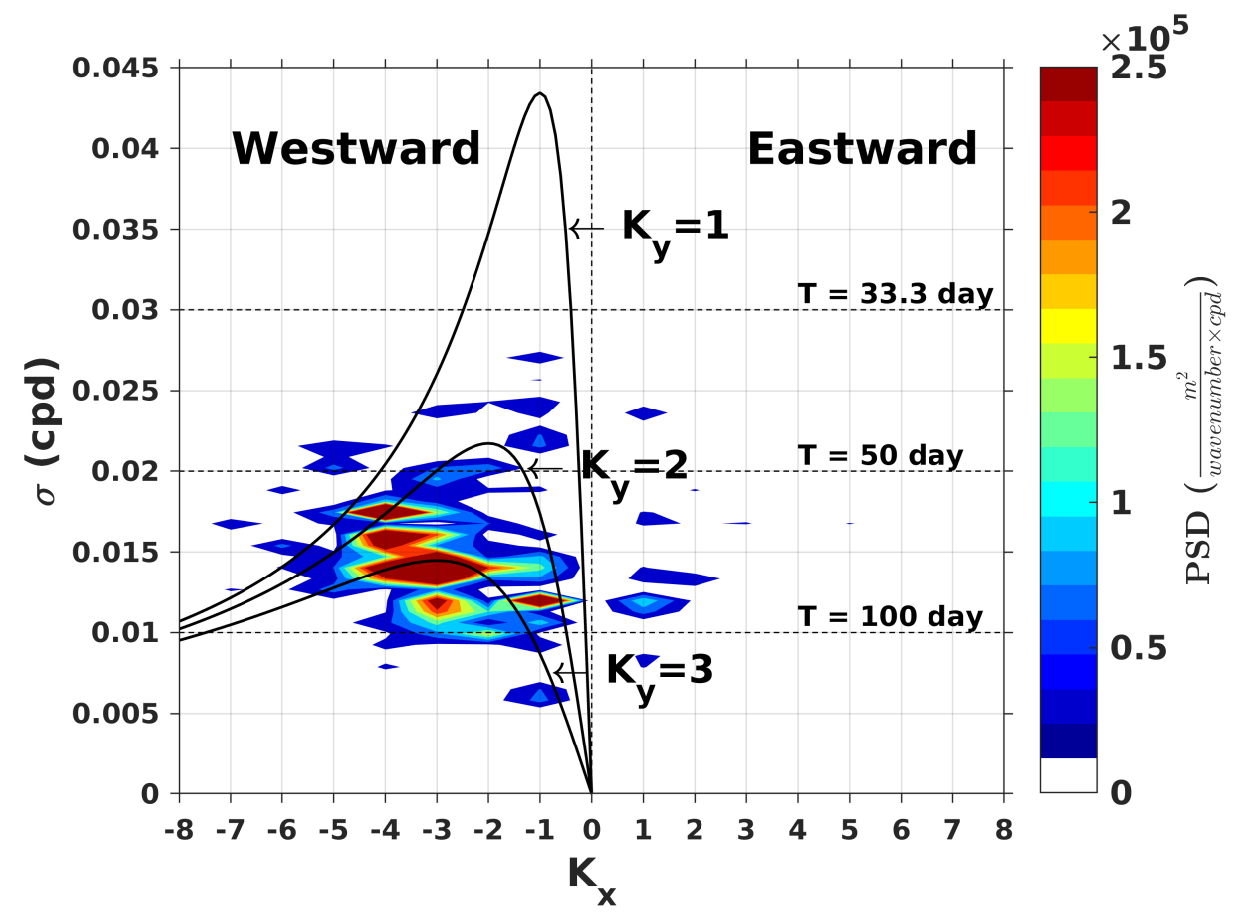

(a)

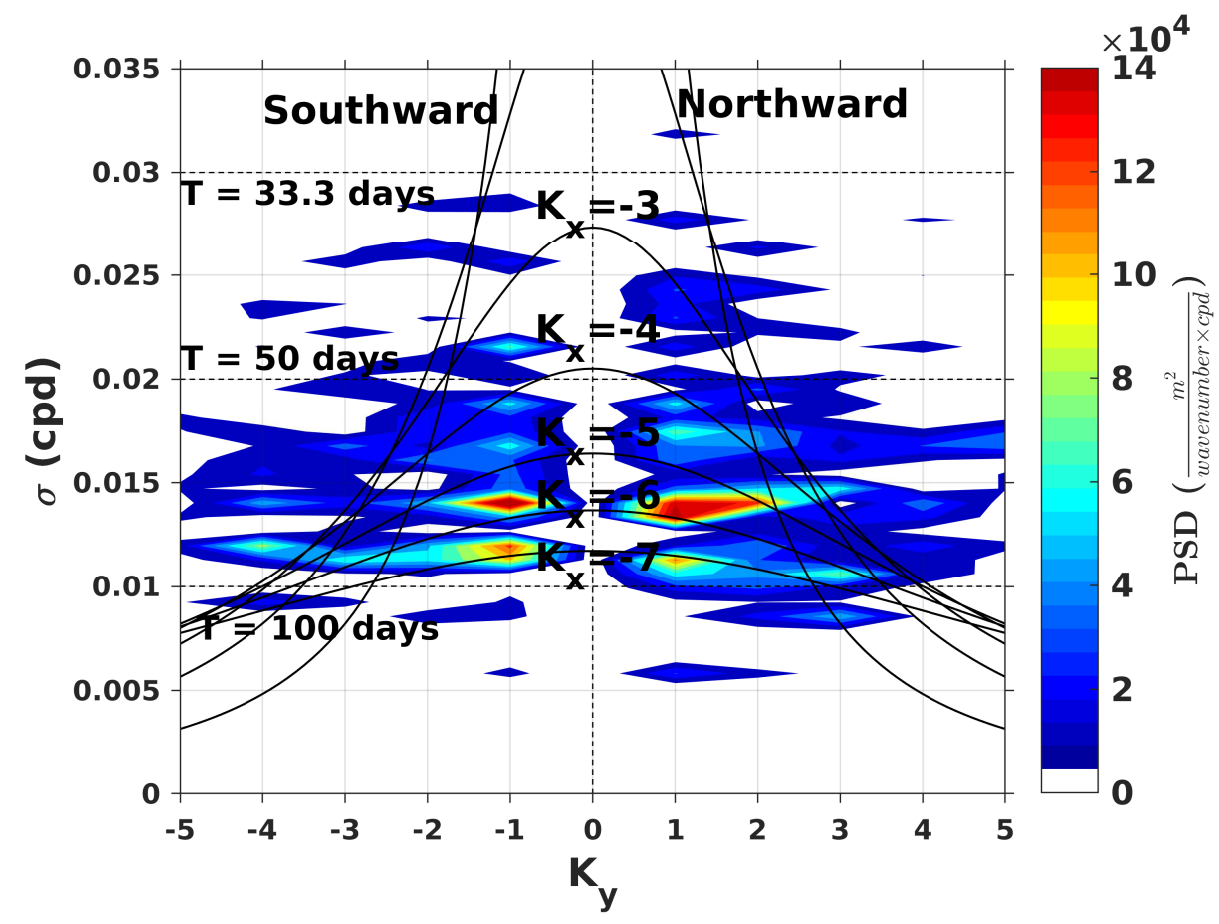

(b)

FIG. 3: Wavenumber-frequency plots of SLA. Panels (a) and (b) show $\sigma-K_{x}$, averaged over $14^{\circ} \mathrm{N}-15^{\circ} \mathrm{N}$ and $\sigma-K_{y}$, averaged over $89.5^{\circ} \mathrm{E}-90.5^{\circ} \mathrm{E}$, respectively. Solid black lines are theoretical linear Rossby wave dispersion curves. 


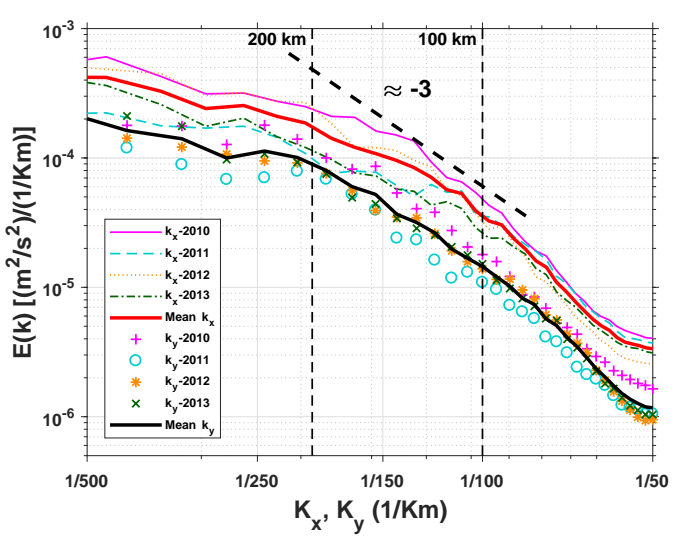

(a)

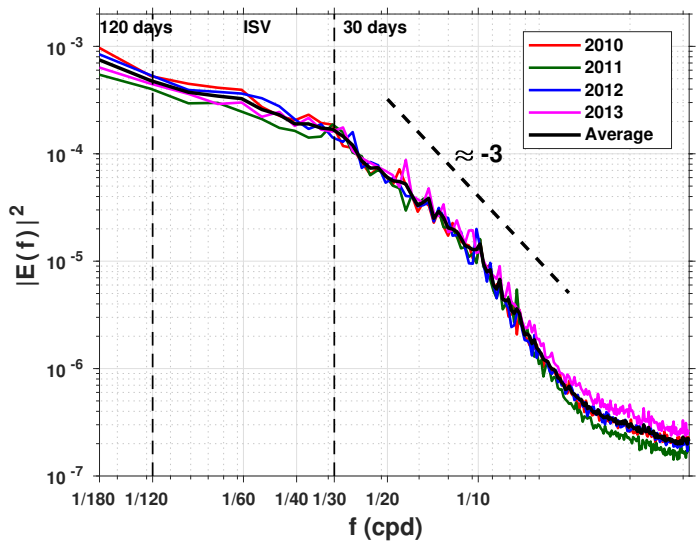

(b)

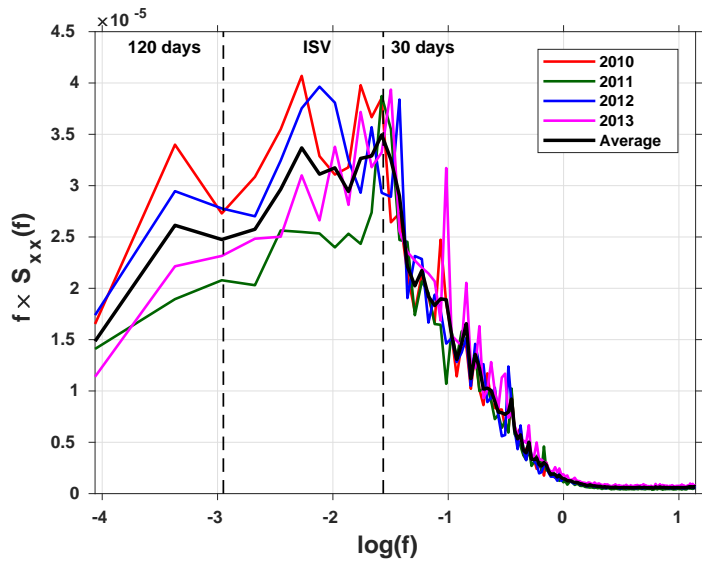

(c)

FIG. 4: Kinetic energy spectra. Panel (a) shows meridional and zonal wavenumber spectra averaged over $11.125^{\circ} \mathrm{N}-12.125^{\circ} \mathrm{N}$ and $89.625^{\circ} \mathrm{E}-$ $90.625^{\circ} \mathrm{E}$, respectively. Panels (b) and (c) contain temporal spectra vs $f$ (frequency) in log-log scale and variance preserving form, respectively. Spectra are estimated at each grid point and then averaged. 

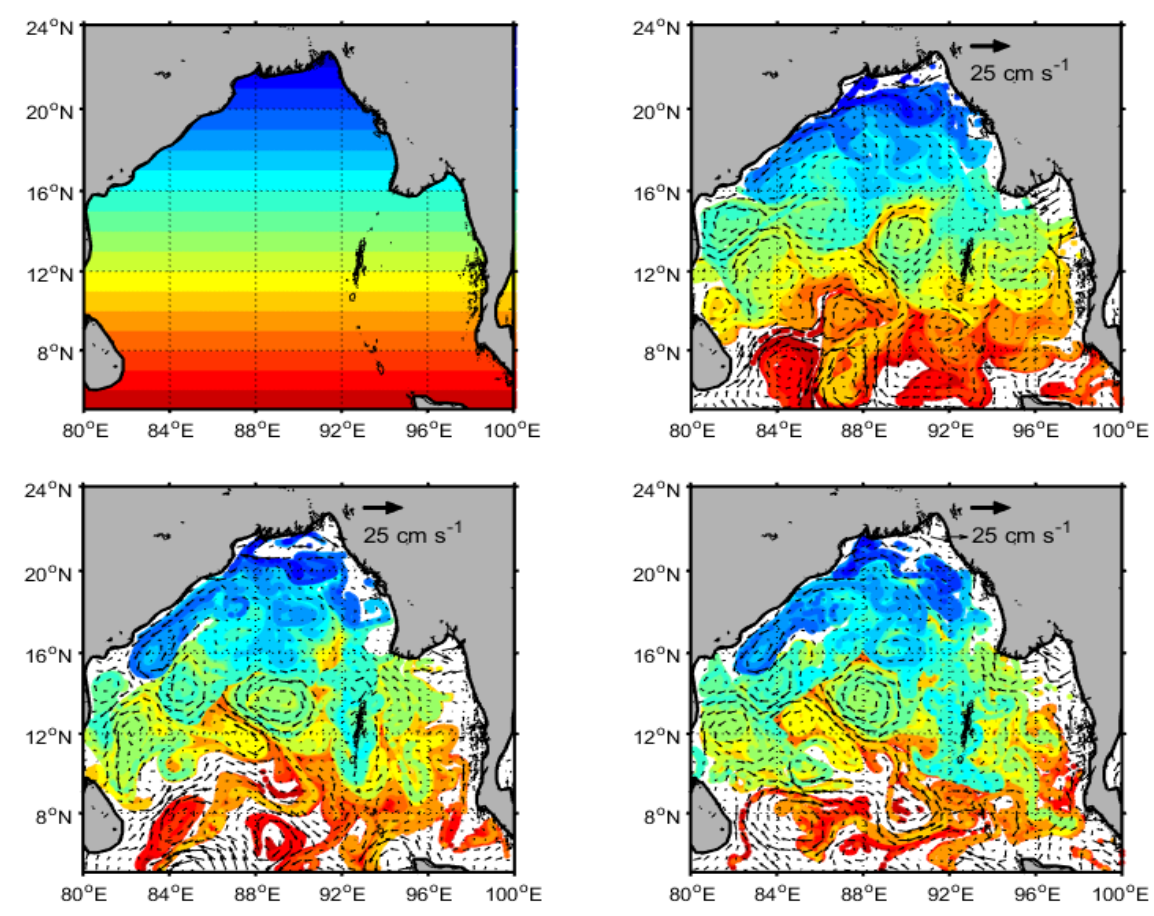

(a)
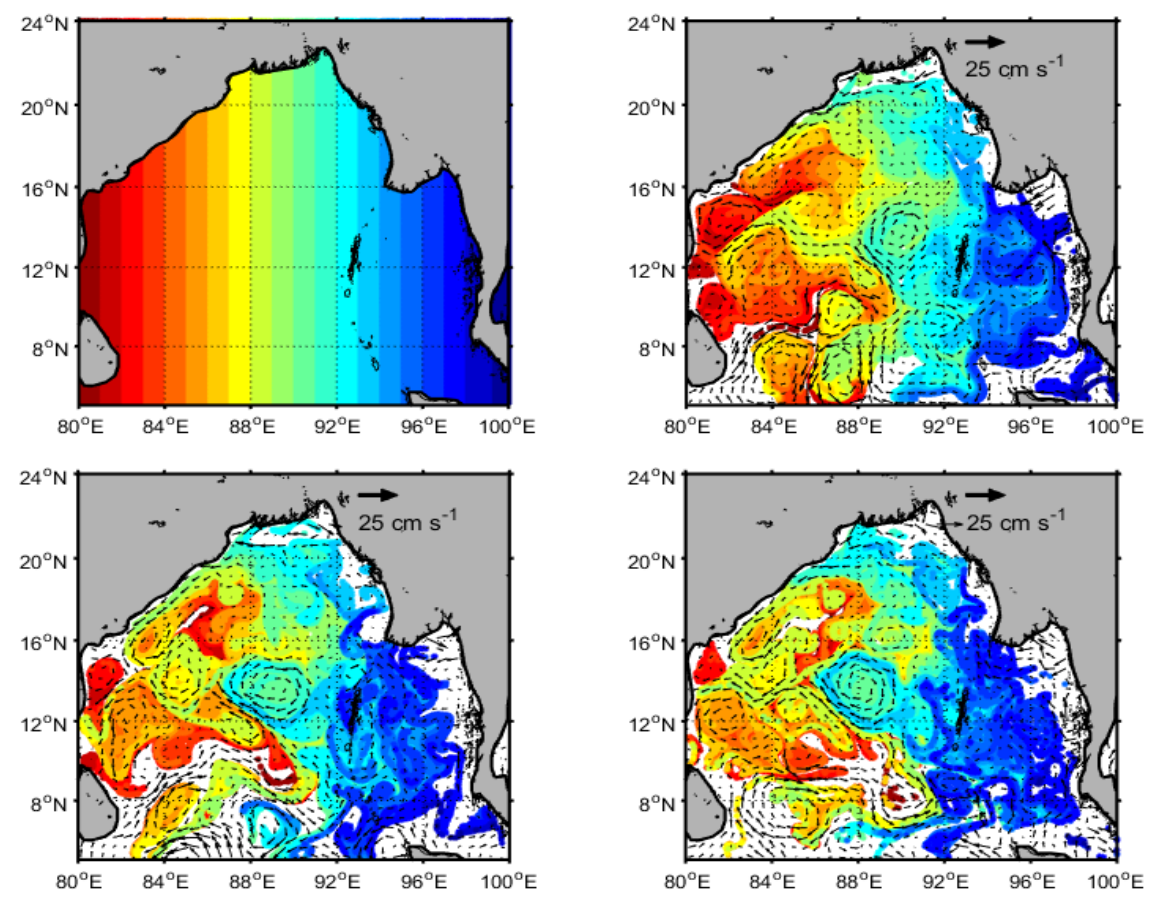

(b)

FIG. 5: The stirring of latitudinal (first four panels) and longitudinal (last four panels) bands by geostrophic currents from September to October 2012. Snapshots are shown every two weeks for six week long advection. 


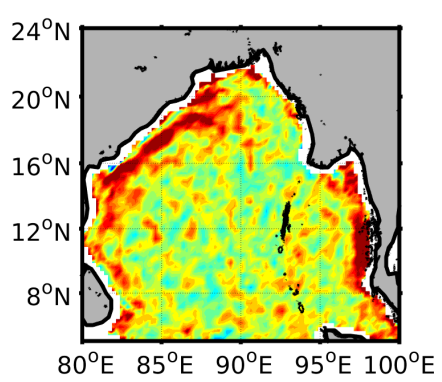

(a)

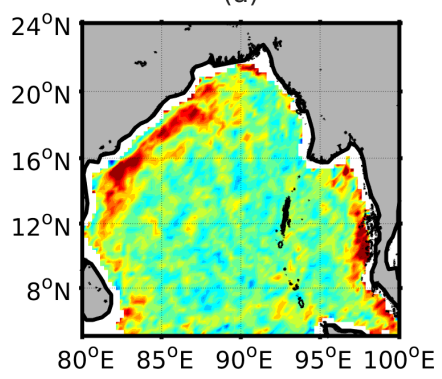

(d)

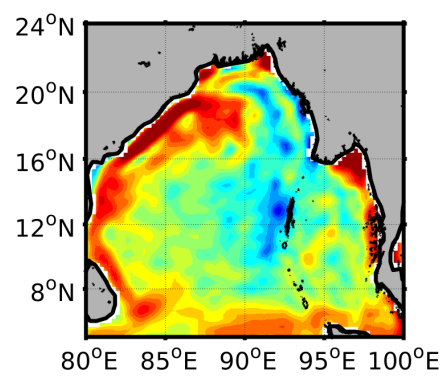

(g)

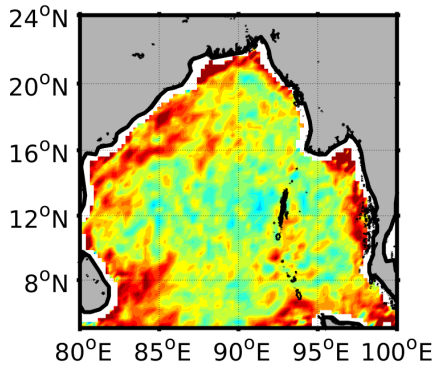

(b)

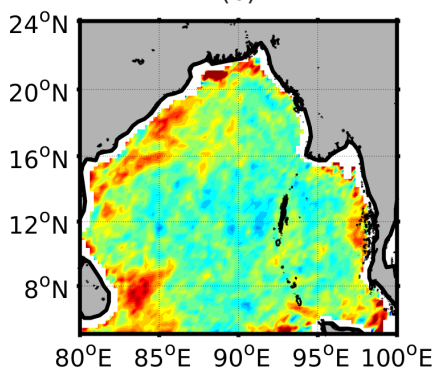

(e)

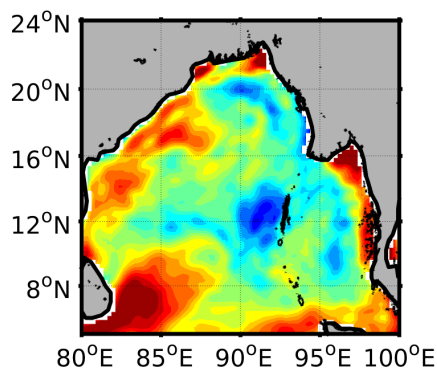

(h)

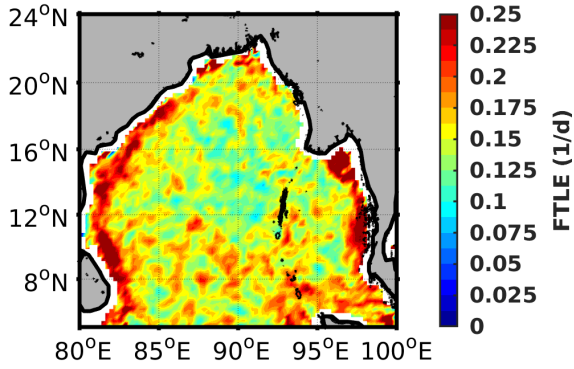

(c)

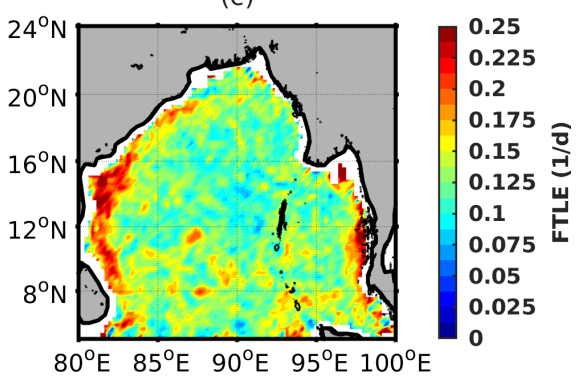

(f)

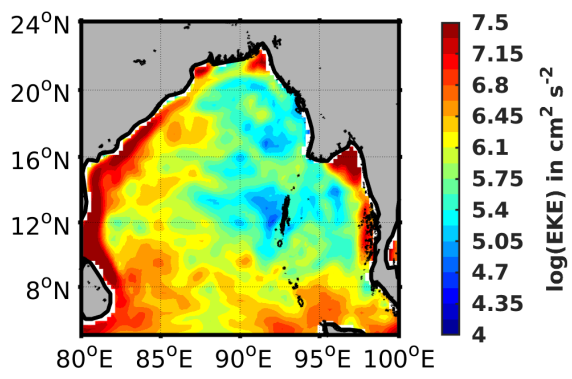

(i)

FIG. 6: Panels (a) and (d) show the FTLE for 5 and 10 days in FMA, (b) and (e) for JJAS, (c) and (f) for the OND season. Panels (g), (h) and (i) show the corresponding eddy kinetic energy for FMA, JJAS and OND seasons, respectively. 


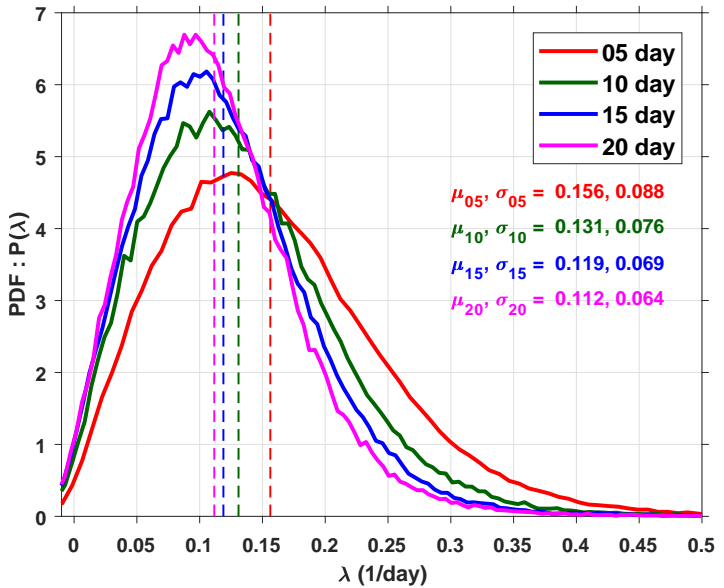

(a)

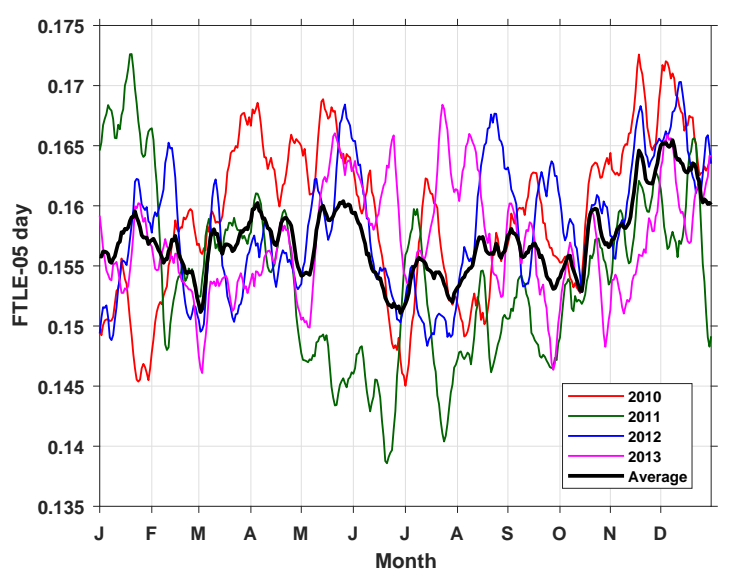

(c)

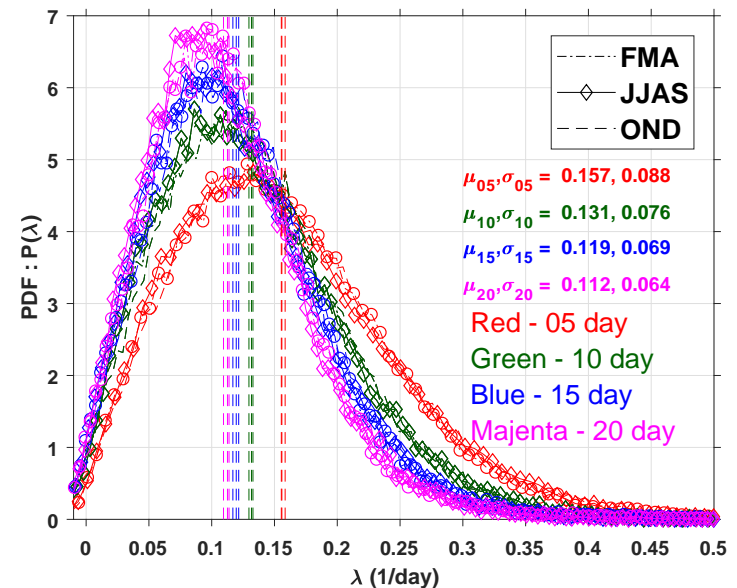

(b)

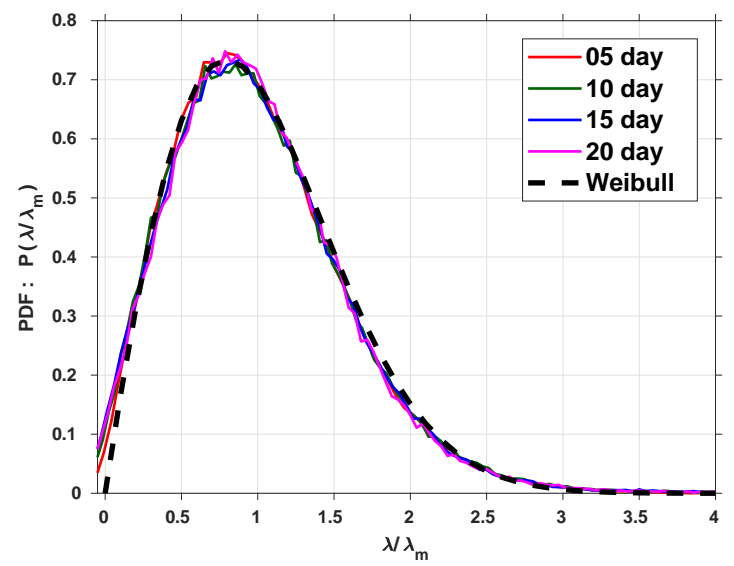

(d)

FIG. 7: Histogram of FTLEs (with different increments) over the Bay; (a) whole year (b) in different seasons. Panel (c) shows the five day mean FTLE time series through the year. Panel (d) shows a fit to the FTLE distribution by a Weibull distribution (normalized by mean $\lambda$ to the FTLE histogram for different $\tau$. 


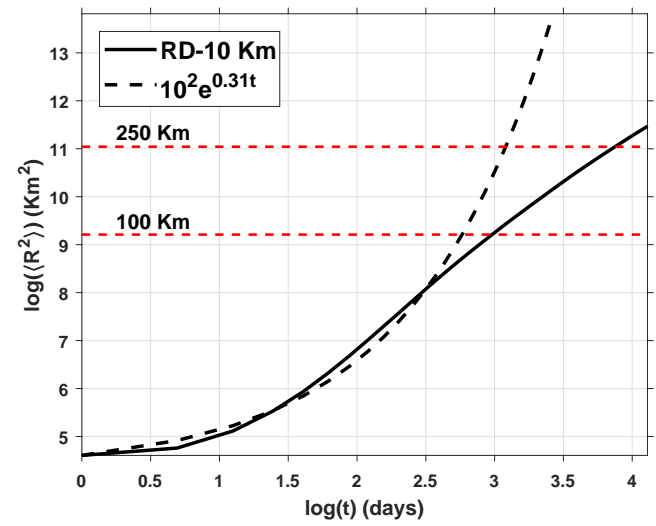

(a)

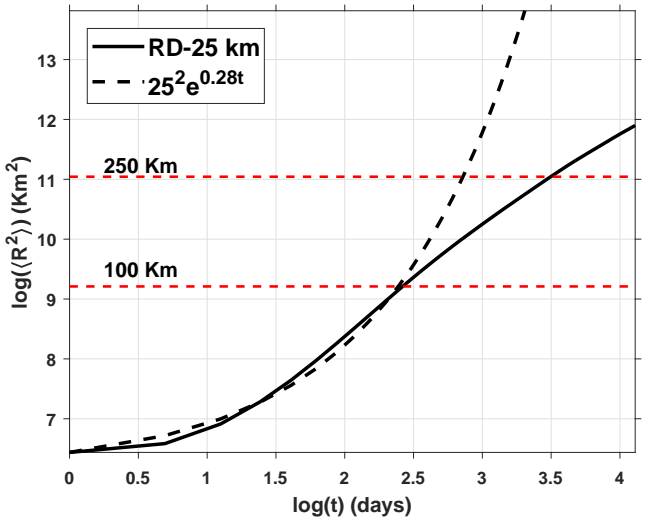

(b)

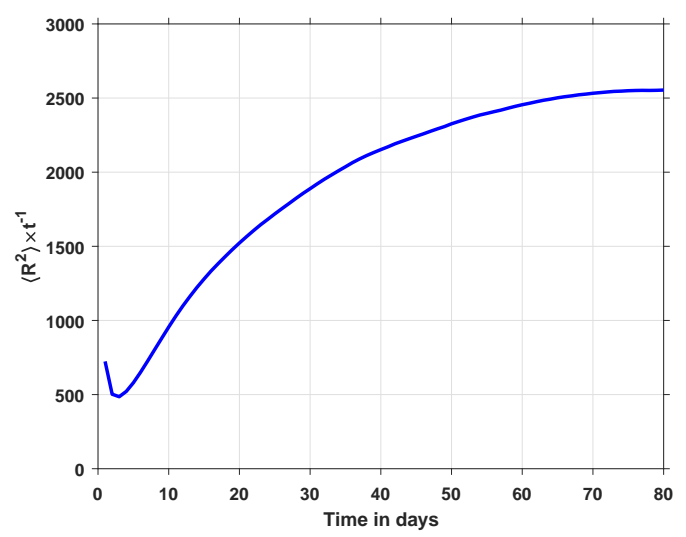

(c)

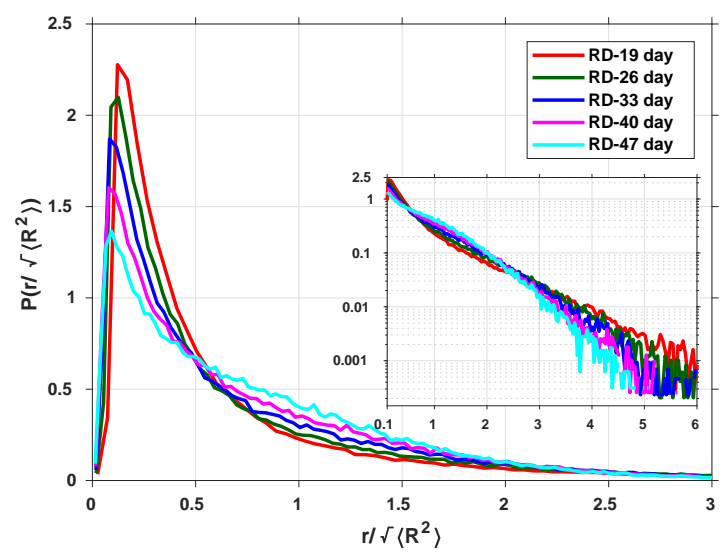

(d)

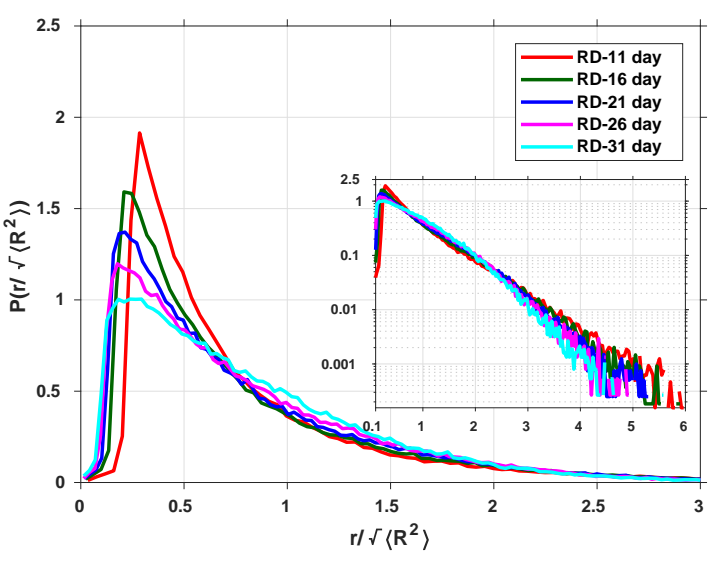

(e)

FIG. 8: Panels (a) and (b) show the RD with time for initial separations of 10 and $25 \mathrm{~km}$, respectively. Panel (c) shows the compensated RD (by $t^{-1}$ ) as a function of time. Panels (d) and (e) show histograms of the square root of RD (denoted by $r$, normalized by its rms value) at different days when the mean RD is between 100 and $250 \mathrm{~km}$. 


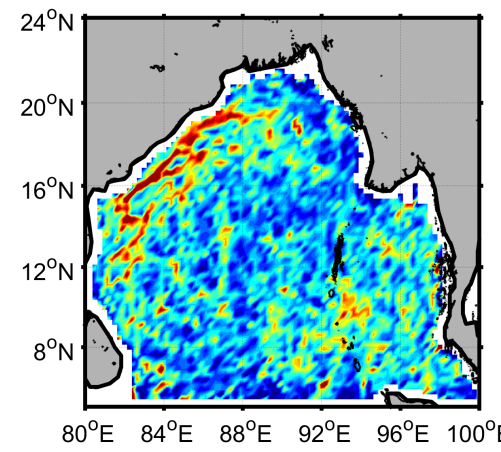

(a)

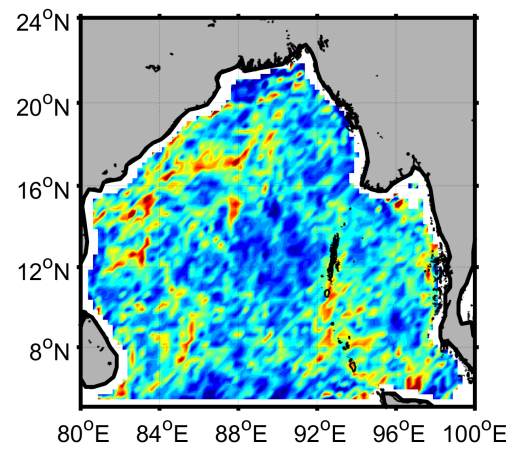

(b)

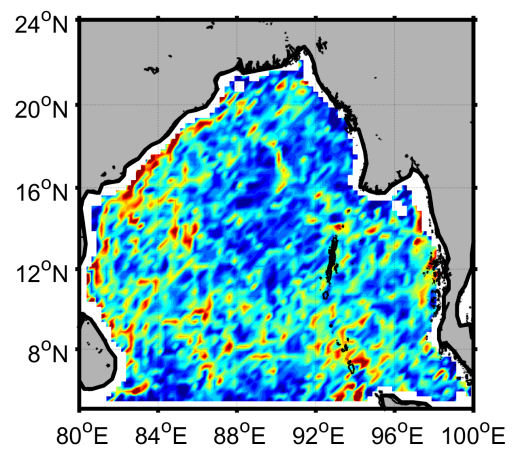

(c)

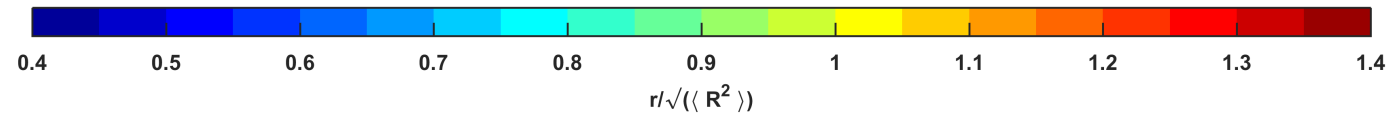

FIG. 9: Panels (a), (b) and (c) show maps of the square root RD (normalized by its rms value) at 15 days from an initial cluster of $25 \mathrm{~km}$ separation in the premonsoon (FMA), monsoon (JJAS) and postmonsoon (OND) periods, respectively.

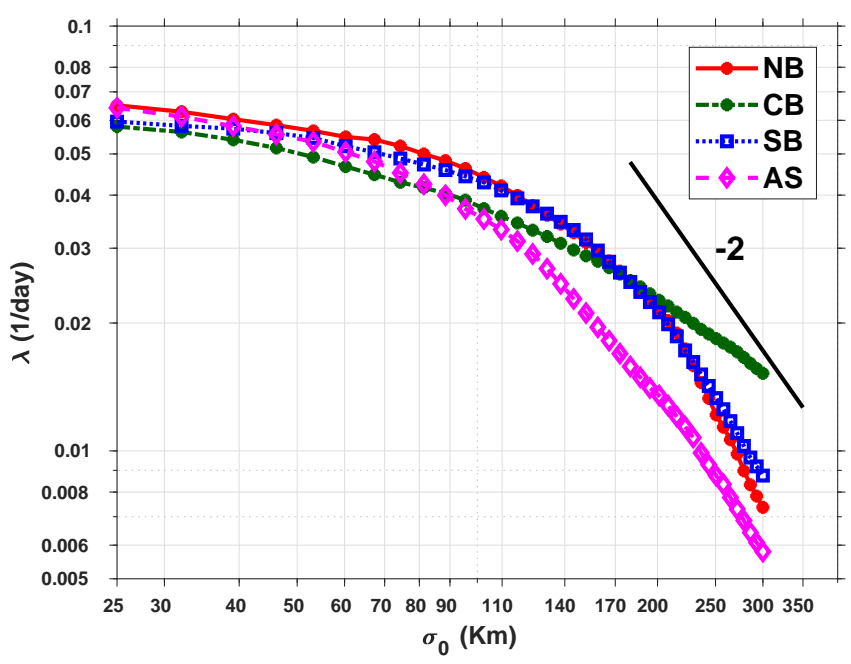

(a)

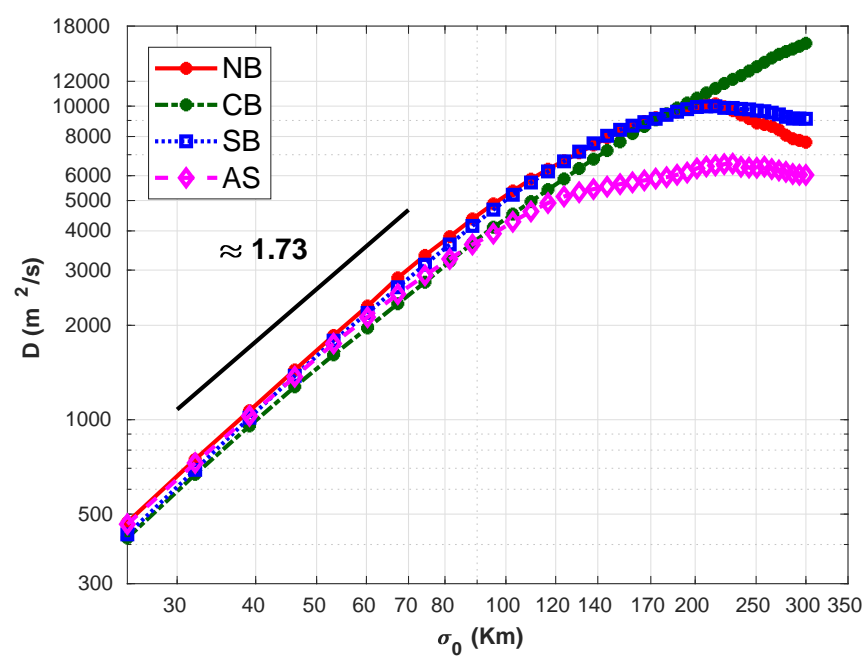

(b)

FIG. 10: Panels (a) and (b) show FSLE and eddy diffusivity as a function of initial cloud size with expansion factor $r=1.2$ for the Northern Bay, Central Bay, Southern Bay and Andaman Sea. 


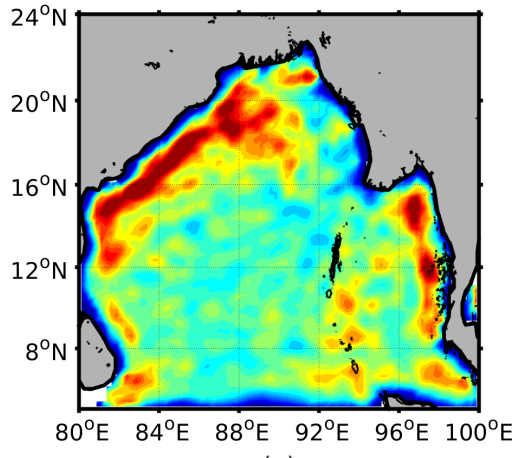

(a)

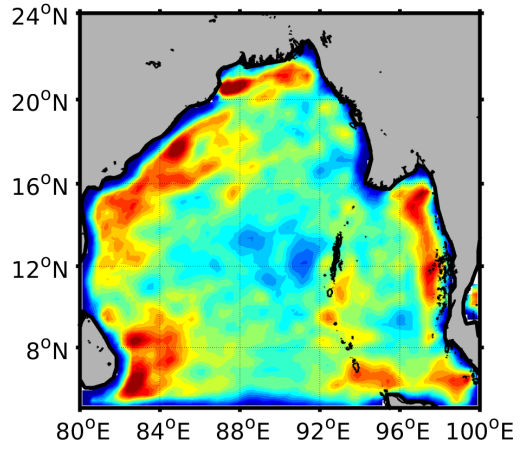

(b)

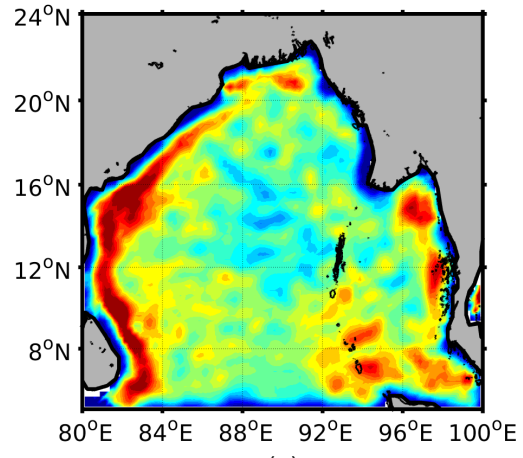

(c)

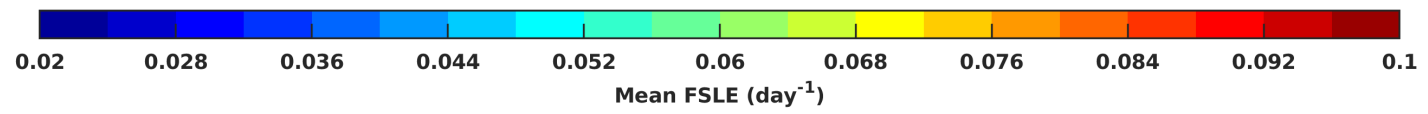

FIG. 11: Panels (a), (b), (c) show the mean FSLE for FMA, JJAS, OND seasons respectively. This is an average over all four years of altimetry data. 

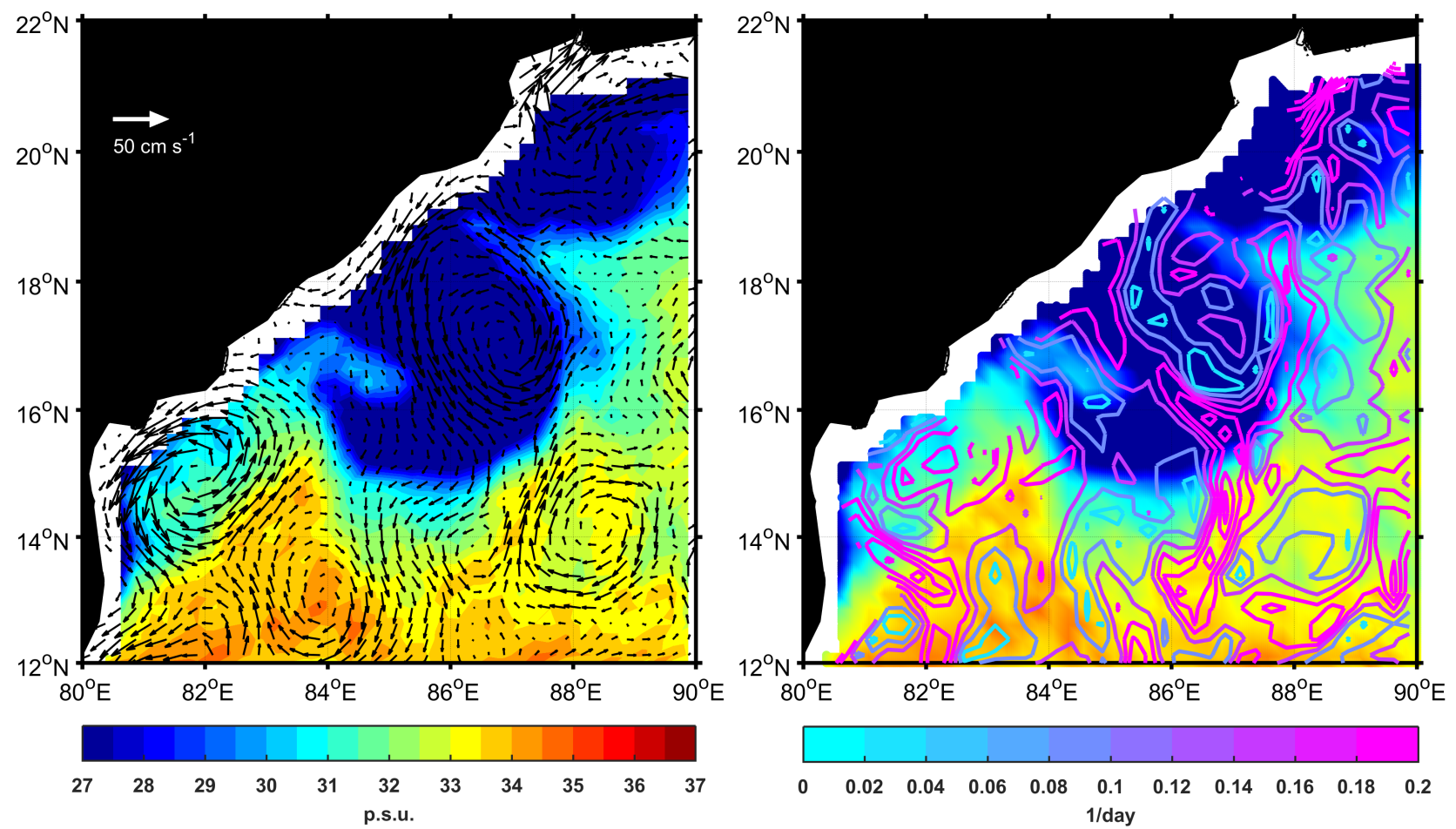

(a)
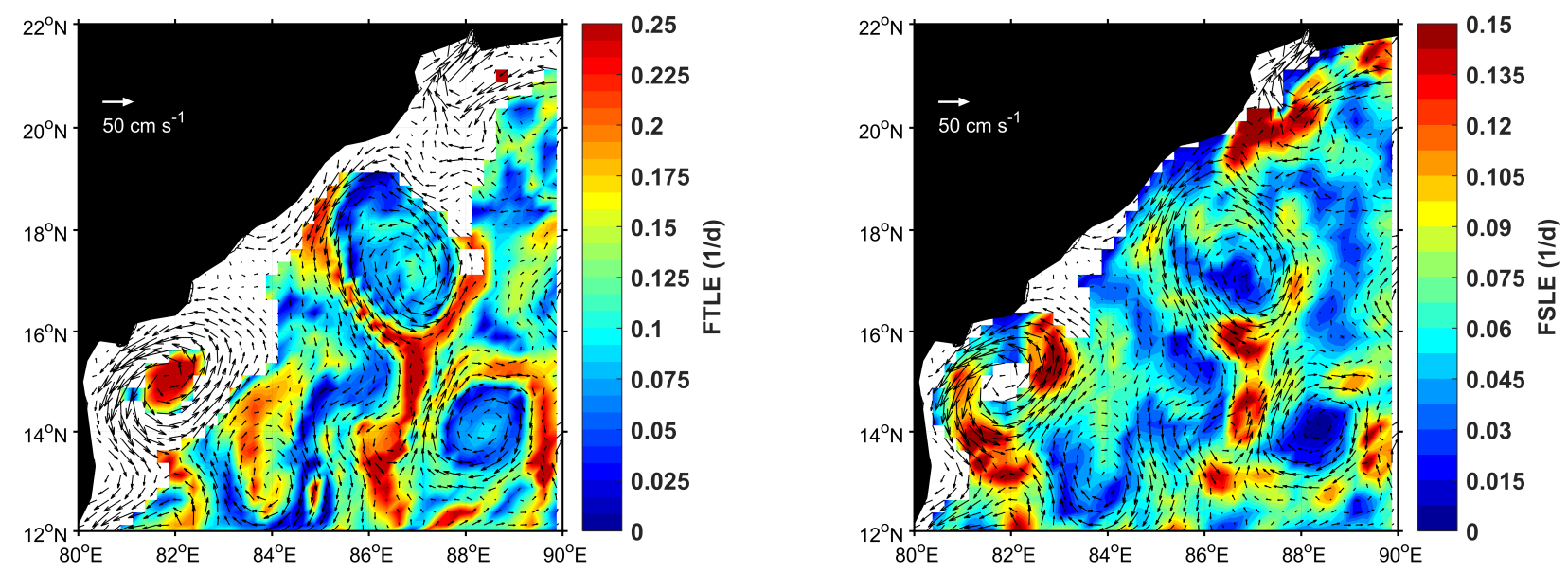

(b)

FIG. 12: Panel (a) shows salinity map with velocity quivers (left) and FTLE-05 day contours overlaid onto passive scalar field (right) on 25/10/2015. Panel (b) shows the spatial map of FTLE-15 day (left) and FSLE (right) on 25/10/2015. 

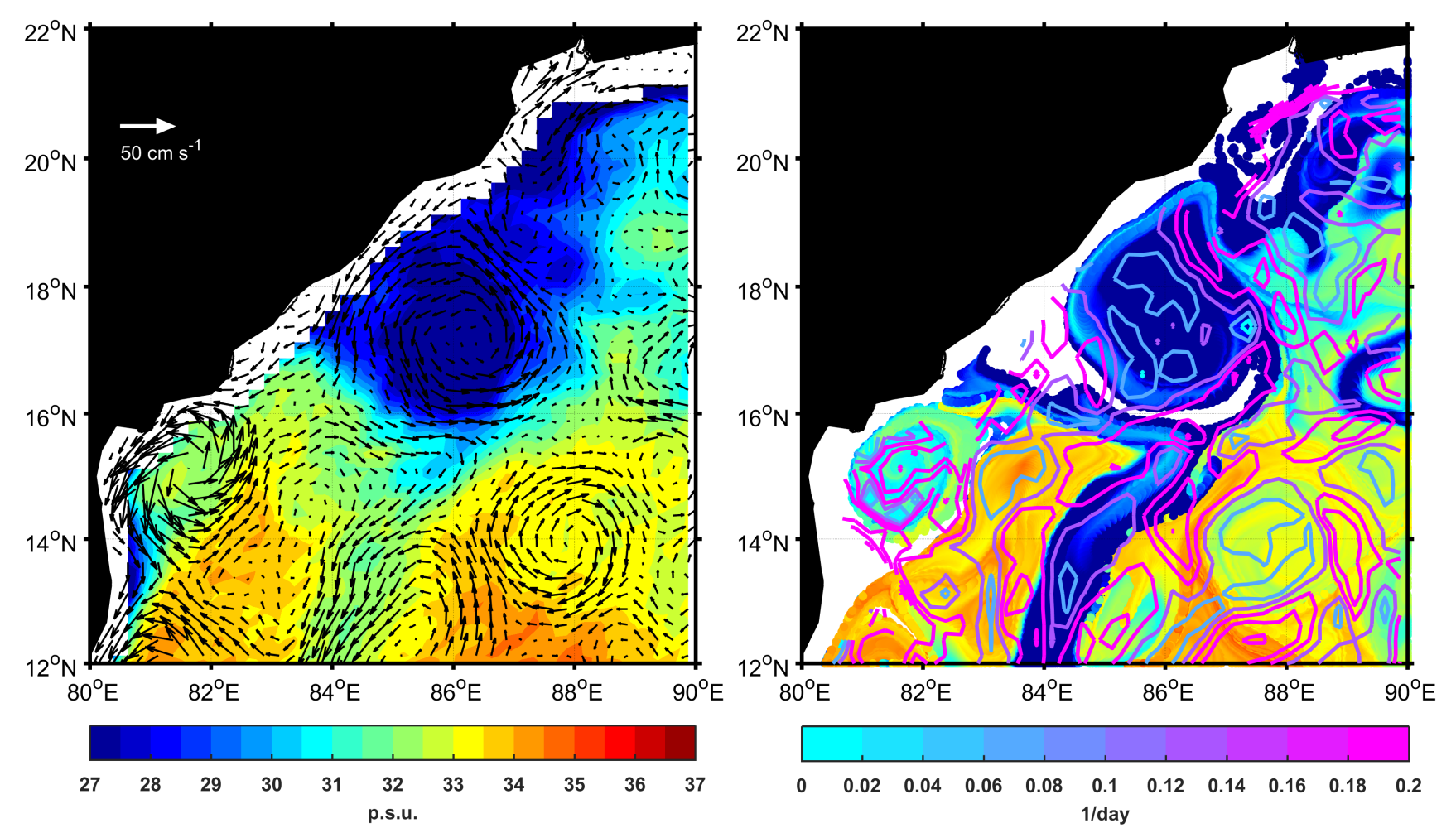

(a)
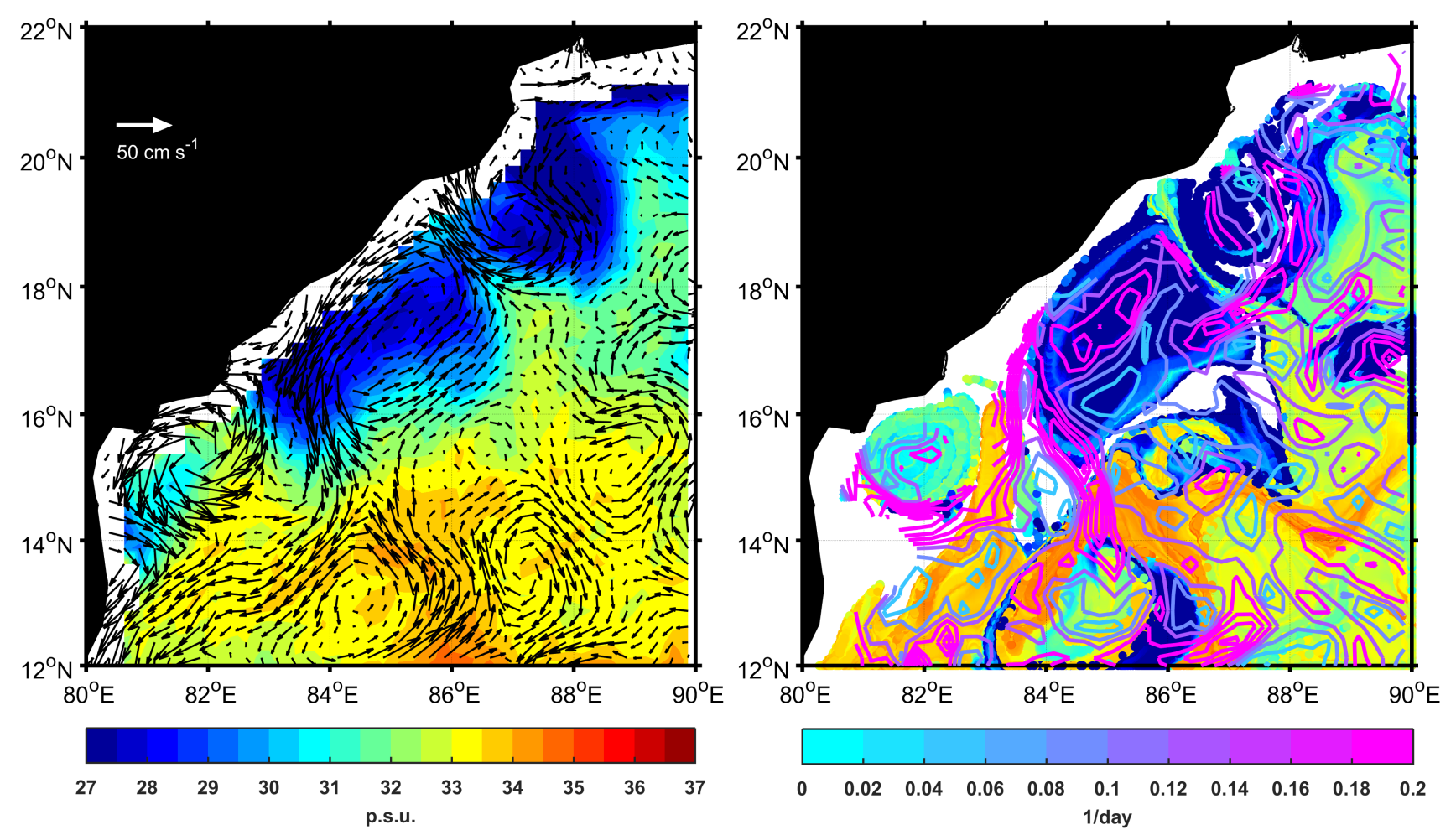

(b)

FIG. 13: Panels (a) and (b) shows salinity map with velocity quivers (left) and FTLE-05 day contours overlaid onto passive scalar field (right) on 08/11/2015 and 24/11/2015, respectively. 